\title{
Advances in ground improvement using waste materials for transportation infrastructure
}

1 Buddhima Indraratna PhD, FTSE, FIEAust, FASCE, FGS Distinguished Professor, Founding Director of Center for Geomechanics and Railway Engineering (CGRE), Director of Australian Research Council's National Training Centre for Advanced Technologies in Rail Track Infrastructure (ITTC-Rail),

University of Wollongong, NSW, Australia (corresponding author: indra@uow.edu.au) (Orcid:0000-0002-9057-1514)

2 Yujie Qi PhD, AMASCE

Associate Research Fellow, Centre for Geomechanics and Railway Engineering, University of Wollongong, Wollongong, Australia (Orcid:0000-0002-3486-2130)

3 Miriam Tawk SMASCE

PhD candidate, Centre for Geomechanics and Railway Engineering University of Wollongong, Wollongong, Australia (Orcid:0000-0002-1317-6297)
4 Ana Heitor PhD, MIEAust Lecturer, School of Civil Engineering, University of Leeds, Leeds, UK; formerly Centre for Geomechanics and Railway Engineering, University of Wollongong, Wollongong, Australia (Orcid:0000-0002-2346-8250)

5 Cholachat Rujikiatkamjorn PhD

Associate Professor, Centre for Geomechanics and Railway Engineering, Australian Research Council's National Training Centre for Advanced Technologies in Rail Track Infrastructure (ITTC-Rail), University of Wollongong, Wollongong, Australia (Orcid:0000-0001-8625-2839)

6 Sinniah K. Navaratnarajah PhD

Senior Lecturer and Lecturer In-Charge of Geotechnical Laboratory, Department of Civil Engineering, Faculty of Engineering, University of Peradeniya, Peradeniya, Sri Lanka (Orcid:0000-0002-7936-520X)
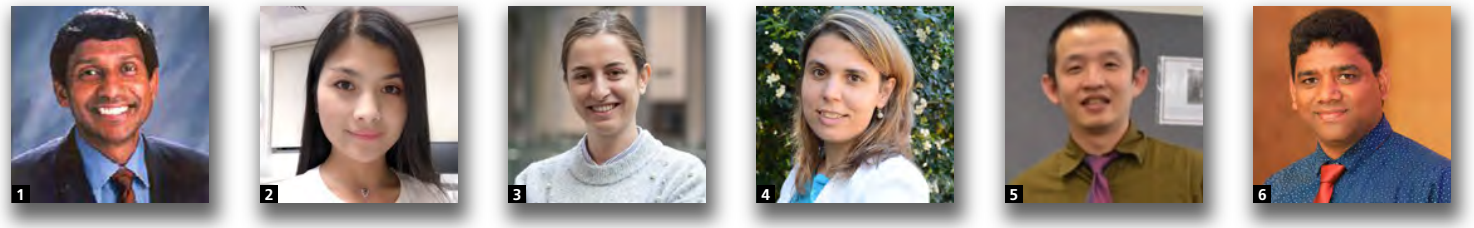

Recycling waste materials for transport infrastructure such as coal wash (CW), steel furnace slag (SFS), fly ash (FA) and recycled tyre products is an efficient way of minimising the stockpiles of waste materials while offering significant economic and environmental benefits, as well as improving the stability and longevity of infrastructure foundations. This paper presents some of the most recent state-of-the-art studies undertaken at the University of Wollongong, Australia on the use of waste materials such as (a) CW-based granular mixtures (i.e. SFS + CW, CW + FA) for port reclamation and road base/subbase and $(b)$ using recycled tyre products (i.e. rubber crumbs, tyre cell, under-sleeper pads and under-ballast mats) to increase track stability and reduce ballast degradation. Typical methods of applying these waste materials for different infrastructure conditions are described and the results of comprehensive laboratory and field tests are presented and discussed.

\section{Introduction}

Stockpiling mining waste has created serious environmental and social concerns for many mining-based countries such as Australia. Steel furnace slag (SFS) and coal wash (CW) are two common granular by-products from steel manufacture and coal mining, and every year millions of tonnes are produced in Australia; most is stockpiled, while the recycling rate barely meets the satisfactory demand (Mudd, 2010). Furthermore, since good quality natural aggregates are becoming increasingly scarce and associated environmental legislation is becoming more stringent, finding sustainable and innovative ways of recycling various types of industry wastes (used tyre derivatives, $\mathrm{CW}$, plastics, glass etc.) for developing civil infrastructure will become crucial (Arulrajah et al., 2020a, 2020b; Indraratna et al., 2018, 2019a; Naeini et al., 2020; Suddeepong et al., 2020). The commercial use of these engineered fills (SFS and CW) above the groundwater level has already been approved by the Environment Protection Authority of the state of New South Wales (NSW EPA, 2014a, 2014b), indicating insignificant leachate potential and toxicity. Humphrey et al. (1997), Edil and Bosscher (1992) and Downs et al. (1996) carried out field studies of shredded rubber above and below the water table and they found insignificant leaching of hazardous compounds - that is, even below the typical limits in drinking water standards.

SFS is produced when converting iron to steel through a basic oxygen furnace (BOF) and $\mathrm{CW}$ is generated while separating coal from its impurities. Apart from $\mathrm{CW}$, fly ash (FA) is another by-product from coal that is generated when burning coal in electricity generation power plants. FA contains some aluminous and siliceous materials that form cement upon chemical reaction with water, and this material is usually considered to be a stabilising agent for base and subbase materials (Ahmaruzzaman, 2010; Wang et al., 2019). While SFS particles have a higher unit weight and superior shear strength and stiffness than natural aggregates (Qi et al., 2018a; Wang, 2010; Yildirim and Prezzi, 2015); previous studies (e.g. Fityus et al., 2008; Heitor et al., 2016; Indraratna, 1994) reported 
that $\mathrm{CW}$ is suitable for structural fill based on its shear strength, and the impact of breakage (during compaction and shearing) and associated double porosity in its compacted state can affect its shear and deformation behaviour significantly (See Kaliboullah et al., 2015; Rujikiatkamjorn et al., 2013). However, improving heterogeneous waste materials such as SFS and CW through compaction poses some challenges related to their individual adverse geotechnical properties that is, the breakage potential for CW (Heitor et al., 2016; Indraratna, 1994) and volumetric instability (swelling) for SFS (Heitor et al., 2014; Wang, 2010). To minimise these detrimental effects and optimise the geotechnical properties, these waste materials are usually blended with other materials before using them for civil engineering applications. For instance, SFS can be blended with FA, cement, asphalt or concrete to serve as a landfill or a pavement material (Malasavage et al., 2012; Xue et al., 2006; Yildirim and Prezzi, 2015), CW is mixed with FA and then used as alternative aggregates for base and subbase materials in roads (Wang et al., 2019), and it has been reported that SFS and CW blended in a proper ratio can successfully serve as construction fill in port and land reclamation projects (Chiaro et al., 2015; Heitor et al., 2014; Indraratna et al., 1994; Tasalloti et al., 2015a, 2015b).

The accumulation of waste tyres is another concern for most developed and developing countries; in Australia alone, more than 50 million (equivalent passenger unit) waste tyres are generated every year (Brulliard et al., 2012). To tackle the problem of large stockpiles of waste tyres, researchers have proposed innovative ways to reuse waste tyre products in civil engineering, especially transport infrastructure projects such as railways, highways and seismic isolation. This is because the high damping property and high energy-absorbing capacity of rubber help to attenuate dynamic loads and vibrations and hence reduce the degradation of infrastructure foundations and enhance stability and longevity (Costa et al., 2012; Indraratna et al., 2018, 2019a; Qi et al., 2018c; Schneider et al., 2011; SolSánchez et al., 2015). Several types of recycled rubber products have been introduced into railways - that is, under-sleeper pads (USP), under-ballast mats (UBM), recycled tyre cells and granulated rubber/rubber crumbs (RC) (Indraratna et al., 2017a, 2017b, 2017c, 2018, 2019b; Jayasuriya et al., 2019; Navaratnarajah et al., 2018; Navaratnarajah and Indraratna, 2017; Nimbalkar and Indraratna, 2016; Sol-Sánchez et al., 2019). Furthermore, mixing RC with mining waste (i.e. SFS, $\mathrm{CW}$ ) can further improve the energy-absorption properties of these waste mixtures and also extend the application of these mining wastes into rail foundations (Indraratna et al., 2017a, 2019b).

This paper reviews the recent novel studies at the University of Wollongong (UOW), Australia, on the use of waste materials (i.e. SFS, CW, FA and recycled tyre products) in port reclamation and roads and railways; these applications include: (a) using blends of SFS and CW for port reclamation; (b) evaluating a mixture of CW and FA for road base/subbases; (c) two methods for developing a synthetic energy-absorbing layer (SEAL) for railway subballast using mixtures of $\mathrm{SFS}+\mathrm{CW}+\mathrm{RC}$ or $\mathrm{CW}+\mathrm{RC} ;(d)$ using recycled tyre cells to reinforce the capping layer for heavy-haul rail tracks; and (e) using rubber mats (i.e. USP, UBM) to reduce ballast degradation and track deformation under stiff subgrade conditions such as tunnels and bridges. Comprehensive laboratory tests (small scale and large scale) were carried out to investigate the geotechnical properties of these novel waste-material inclusions. The details of general test procedures and typical sample preparation process have been described elsewhere (e.g. Chiaro et al., 2015; Indraratna et al., 2017a), where the target material is based on optimising the blended materials in various proportions according to the type of infrastructure and the nature of loading anticipated. These research outcomes are expected to contribute to better design solutions, where recycled materials are used to enhance the stability and longevity of infrastructure, while simultaneously reducing the number and volume of waste stockpiles and the demand for natural aggregates.

\section{CW-based waste granular materials for roads and port reclamation}

\subsection{Compacted CW with blends of SFS for port infrastructure}

\subsubsection{Materials}

Using locally available granular waste materials such as $\mathrm{CW}$ and SFS for reclamation fills in port infrastructure is an economical alternative to conventional (quarried) aggregates and dredged sandy fills. CW is a by-product from the washery process for refining run-of-mine (ROM) coal. For every metric tonne of ROM coal that enters a washery plant, approximately $200 \mathrm{~kg}$ of the output are granular waste materials, of which $80 \%$ corresponds to coarse-grained $\mathrm{CW}$ and $20 \%$ are finegrained tailings. Coal mining operations in Australia alone generate millions of tonnes per year of $\mathrm{CW}$ (Chiaro et al., 2015). SFS by-product is a direct result of steelmaking as iron and steel scrap are processed with lime at high temperatures in a $\mathrm{BOF}$ and an electric arc furnace (EAF). Approximately $10-15 \%$ of the output by weight from a BOF is SFS. In this study, the source CW (specific gravity $G_{\mathrm{s}}=2 \cdot 27$ ) is Dendrobium CW produced by Illawarra Coal, and the SFS $\left(G_{\mathrm{s}}=3 \cdot 34\right)$ is produced by way of the basic oxygen method at Australia Steel Milling Services. Their particle-size distribution (PSD) curves are given in Figure 1.

\subsubsection{Applications in port conditions and results of field trials}

The typical specifications of fill materials for port conditions rely on characterising the material in terms of its shear strength (i.e. peak friction angle, $\phi_{\text {peak }}^{\prime}>30^{\circ}$ ) and permeability (between $1 \times 10^{-6}$ and $1 \times 10^{-4} \mathrm{~cm} / \mathrm{s}$ (Davies et al., 2011)). However, for the $\mathrm{CW}$ and $\mathrm{CW}+\mathrm{SFS}$ blends, additional parameters such as 


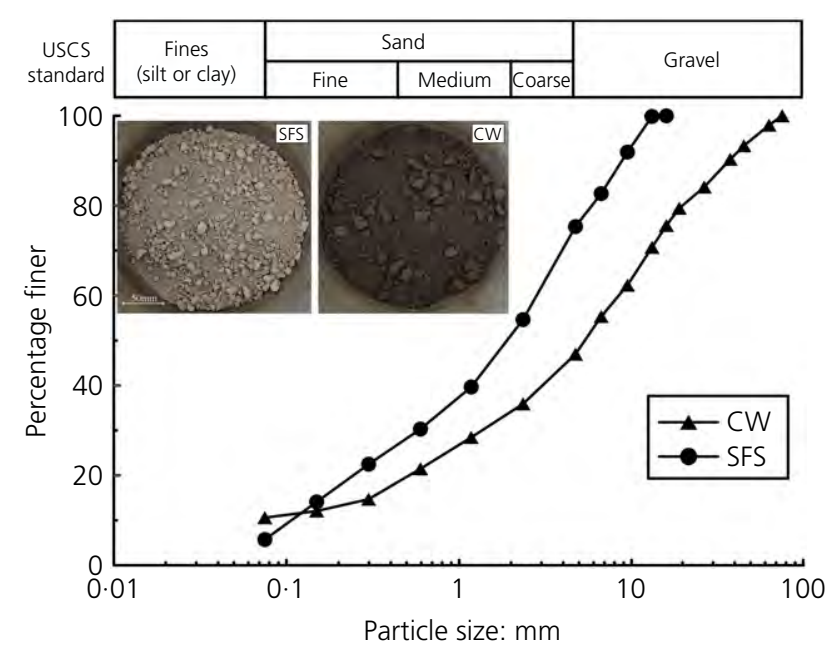

Figure 1. PSD and typical aspect of SFS and CW granular waste by-products. USCS, Unified Soil Classification System

(source: modified after Tasalloti et al. (2015a))

the breakage potential and swelling must be considered. While compacted $\mathrm{CW}$ can easily exceed the required peak friction angle of $30^{\circ}$, it still exhibits excessive breakage during shearing. This is very evident when the stress levels are higher than the critical breakage stress of $127 \mathrm{kPa}$ (Heitor et al., 2016), and this is why Chiaro et al. (2015) proposed modified criteria for selecting an optimal CW + SFS blend ratio that meets the specifications established for port conditions and complies with the allowable volumetric changes during service. The proposed criteria have four levels of acceptance, as shown in Figure 2. The region that defines the optimal mixing ratio of $\mathrm{CW}+\mathrm{SFS}$ lies between $55 \%<\mathrm{CW}<70 \%$; within this range the blends can easily comply with the acceptance criteria defined for structural fill.

Once suitable $\mathrm{CW}+\mathrm{SFS}$ blend ratios were identified, a field trial took place at the Port Kembla Outer Harbour reclamation site in an area $55 \mathrm{~m}$ long $\times 14 \mathrm{~m}$ wide $\times 1.4 \mathrm{~m}$ deep (i.e. $1078 \mathrm{~m}^{3}$ ) assigned by the Port Kembla Port Corporation. This area was then divided into two sections so that the two selected blends could be assessed. The ratios of these mixtures were based on a preliminary study conducted by Chiaro et al. (2015) - that is, CW50 + SFS50 and CW20 + SFS80 by volume percentage. The materials were mixed and placed in situ by an excavator, and then spread and levelled with a grader (Figure 3(a)). The CW + SFS blends were compacted by a $13 \mathrm{t}$ smooth steel drum roller running on a vibration mode of $30 \mathrm{~Hz}$ (Figure 3(b)). After four to eight passes with the roller, the mixtures could attain 90-95\% dry unit weight complying with the required specifications for port expansion (Davies et al., 2011).

Dynamic cone penetration tests (DCPTs) and plate load tests (PLTs) were then carried out to assess the post-compaction shear strength of these mixtures. During the DCPT tests, the number of blows to drive the cone penetrometer $100 \mathrm{~mm}$ into the compacted layers was measured regularly (ASTM, 2009); Figures 3(c) and 3(d) show the equivalent in situ California bearing ratio $(\mathrm{CBR})$ values obtained by way of the number of DCPT blows $\left(C B R=292 /\right.$ DCP $\left.^{1 \cdot 12}\right)$ following ASTM (2009). Since these mixtures had an equivalent CBR value between 25 and 50 , they could be considered suitable for a structural fill in terms of their shear strength.

PLTs for each mixture were carried out at two elapsed time periods to investigate the potential effects of the hydration reactions due to the presence of free lime $(\mathrm{CaO})$ and free magnesium $(\mathrm{MgO})$ in the SFS. The variation of applied pressure with settlement, for the two stages (i.e. 30 and $170 \mathrm{~d}$ after compaction) is shown in Figures 3(e) and 3(f). Not surprisingly, the blend with a higher percentage of SFS (Figure 3(f)) had the largest difference between the 30 and $170 \mathrm{~d}$ tests. From the viewpoint of post-construction settlement and the expected port service loads $(60-120 \mathrm{kPa})$, the expected settlement would not exceed $1 \mathrm{~mm}$; this result confirmed the blend's suitability as a structural fill.

The presence of calcium oxide and magnesium oxide in the SFS may cause the mixtures to experience swelling. To investigate the swelling potential (ratio of vertical expansion to the layer thickness), surface markers were monitored over time with surveying equipment. While the mixture with a higher SFS showed more swelling, it was still modest for a free swelling condition; the swelling potential of the CW50 + SFS50 and CW20 + SFS 80 blends were 5 and $6 \cdot 3 \%$, respectively. On this basis, and provided that the surcharge and live loads (e.g. pavement, live loads) are greater than the swell pressure (approximately $50 \mathrm{kPa}$ for CW50 + SFS50), vertical expansion should not occur, and moreover, it is unlikely the swelling potential would influence the performance and stability of the built port infrastructure.

\subsection{Evaluating CW + FA mixtures for road base/subbase}

SFS has a great potential for swelling and its use in ground engineering projects is contingent on the amplitude of live loads to counteract the swelling pressure. Loads at the level of the base/subbase of roads may not be enough to prevent swelling and undesirable deformations. A mixture of CW and $\mathrm{FA}(\mathrm{CW}+\mathrm{FA})$ is another alternative to natural rock aggregates for base/subbase material in roads, with the FA being added to fill the voids and increase the density of the mixture and improve particle interlocking for increased strength. A comprehensive optimisation study has been carried out on several mixtures of CW and FA using different amounts of FA; this experimental study is summarised in Figure 4 (Wang et al., 2019).

\subsubsection{Selecting the optimum FA content}

To evaluate the effect that FA has on compaction efficiency, a standard Proctor compaction was carried out on a mixture 


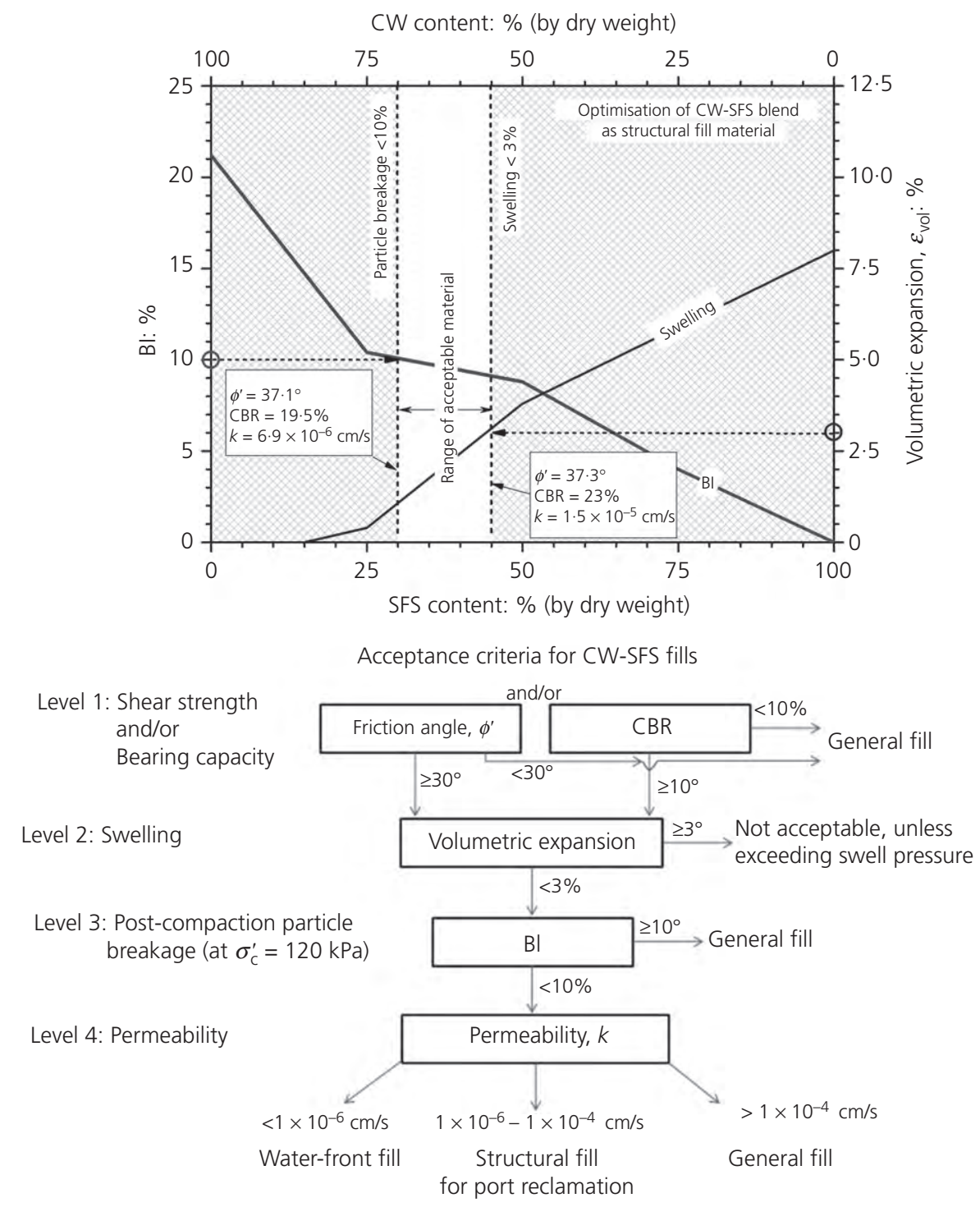

Figure 2. Criteria for defining the optimal CW-SFS blend (source: modified after Chiaro et al. (2015))

where the amounts of FA ranged between 0 and $20 \%$. Since the components of this mixture had different specific gravities, the compaction efficiency was represented by the void ratio rather than the dry density. Figure 5 shows that the void ratio decreases as the amount of FA increases up to $10 \%$, after which the void ratio begin to increase again. These preliminary results prove that the optimum amount of FA is around $10 \%$. In practice, however, the compaction energy is often higher than the standard Proctor compaction tests, so based on the results of the standard Proctor compaction, modified Proctor compaction tests were carried out on smaller amounts of FA (i.e. $7 \%, 10 \%$ and 13\%) to mimic field conditions. Figure 5(b) shows that the minimum void ratio corresponds to $7 \%$ FA and $6 \%$ water content; however, the compaction curve became flatter as the amount of FA increased beyond 7\%. This indicates that larger amounts of FA can reduce the compaction efficiency, regardless of water content. The strength and deformation of $\mathrm{CW}+\mathrm{FA}$ mixtures were further evaluated based on their unconfined compressive strength (UCS), the CBR and the collapse potential (CP), to verify that $7 \%$ is the optimum amount of FA needed to improve their geotechnical behaviour.

The UCS of CW + FA mixtures compacted at a modified Proctor energy was studied as per SA 5101.4 (SA, 2008). The samples were prepared under different moisture contents in relation to the optimum moisture content (OMC) determined based on the modified Proctor compaction curve. Moisture contents were selected to cover both the dry side and the wet side of OMC to evaluate the effect of moisture content on the strength of the mixture with varying FA contents (see Table 1). Figure 6(a) shows that the maximum UCS at OMC (i.e. 6\%) corresponds to $7 \%$ FA. On the wet side of OMC, the mixture 
Indraratna, Qi, Tawk et al.

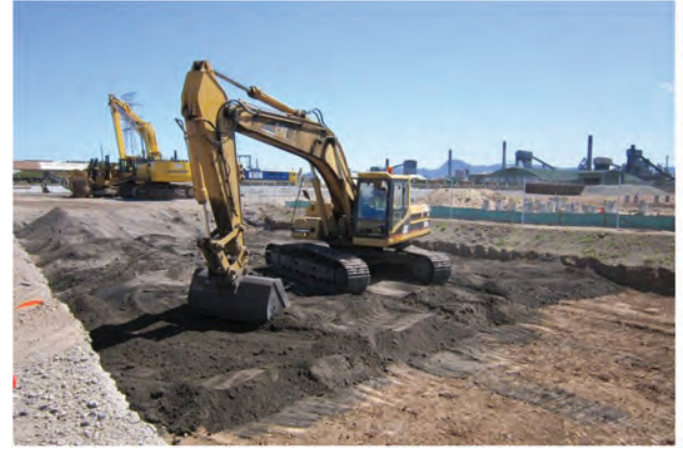

(a)

Equivalent in situ CBR

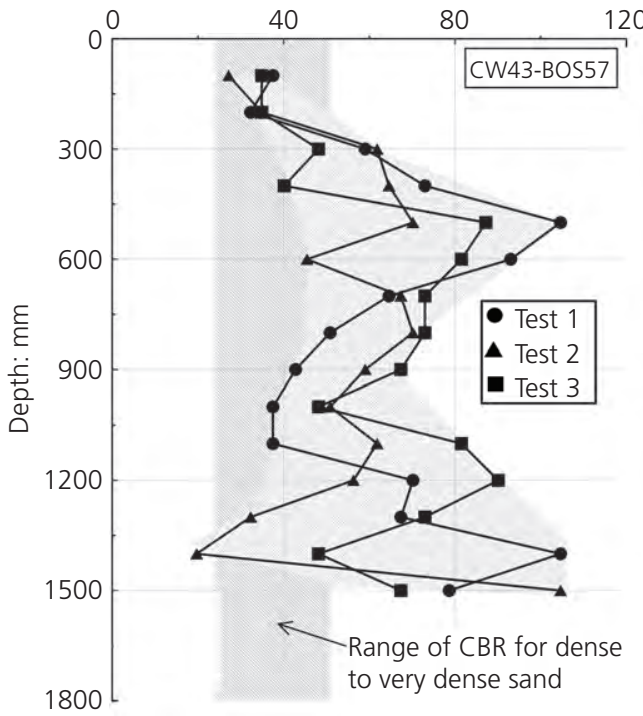

(c)

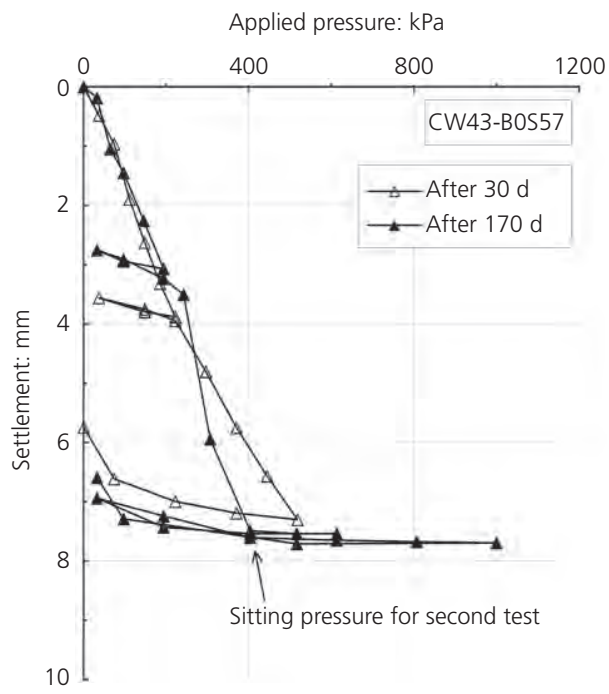

(e)

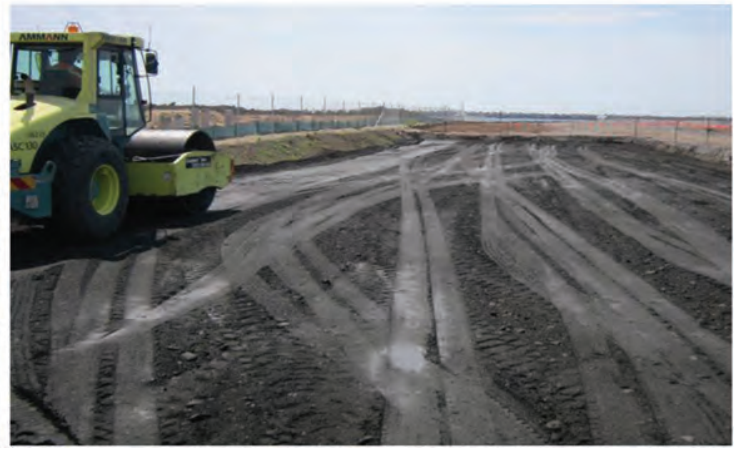

(b)

Equivalent in situ CBR

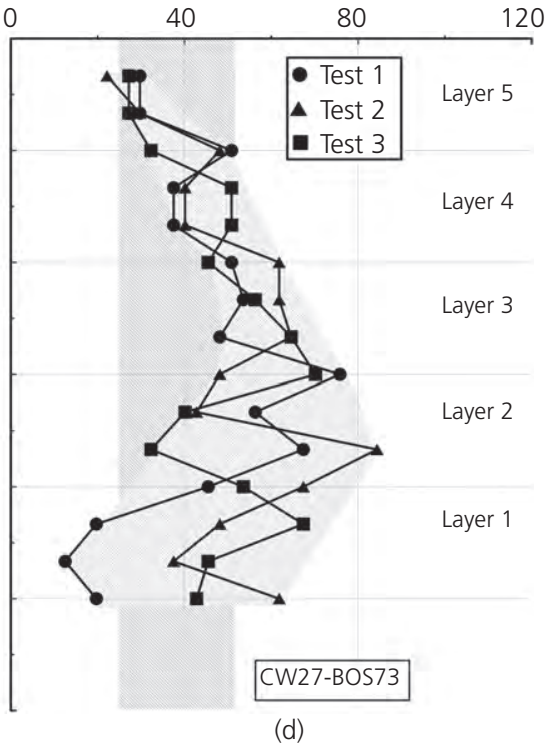

Applied pressure: $\mathrm{kPa}$

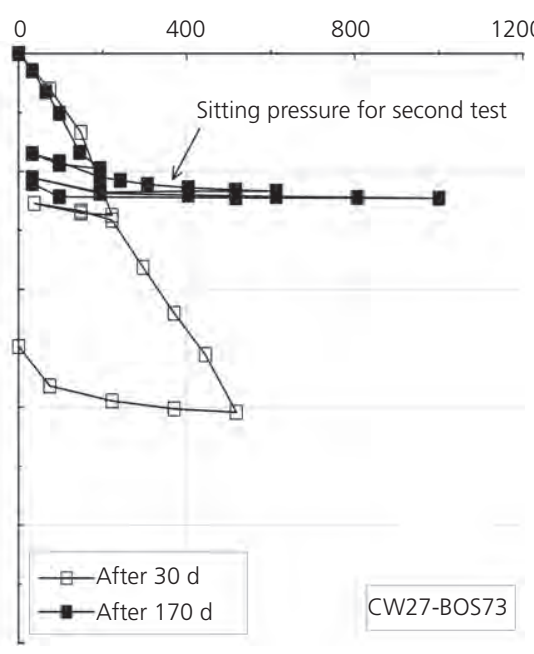

(f)

Figure 3. Photographs of the field trial: (a) spreading mixed materials; (b) compaction. (c), (d) Variation of the equivalent in situ CBR with depth; (e), (f) variation of pressure against settlement for CW50-BOS50 (basic oxygen slag) and CW20-BOS80 (source: modified after Tasalloti et al. (2015b)) 


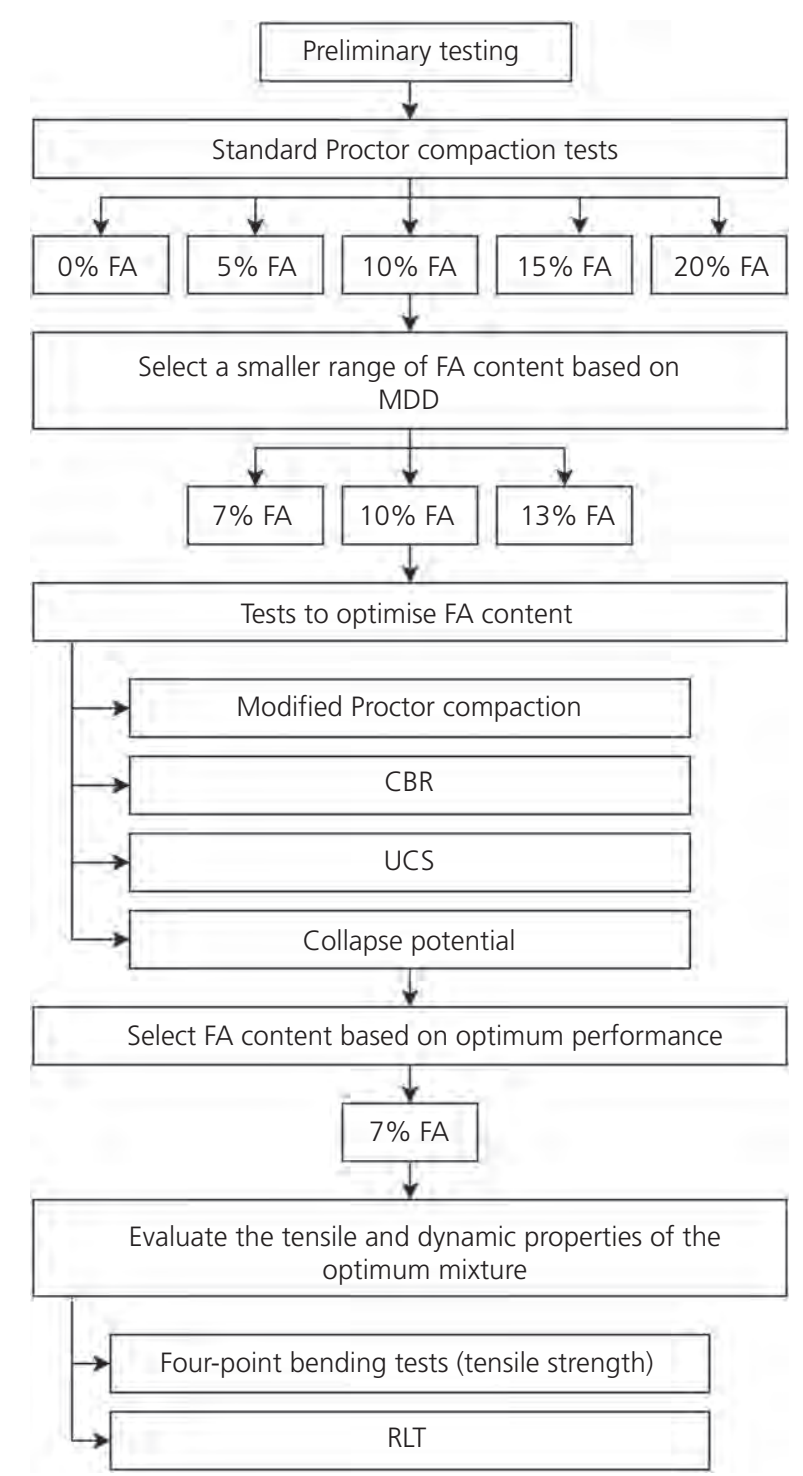

Figure 4. Experimental study for the optimisation of a $C W+F A$ mixture (source: modified after Wang et al. (2019))

with 7\% FA has the highest UCS and the mixture with $13 \%$ FA has the highest UCS on the dry side of OMC. However, very dry conditions are not suitable in practice because they induce brittle behaviour that results in tensile cracking. The UCS of the mixture with $7 \%$ FA (i.e. $250 \mathrm{kPa}$ ) is lower than $1000 \mathrm{kPa}$, which is the maximum allowed for base/subbase material in roads needed to avoid extreme brittle behaviour. Figure 6(b) also shows that the minimum axial strain at the maximum UCS corresponds to $7 \% \mathrm{FA}$ at $\mathrm{OMC}$, and this increases slightly at $\mathrm{OMC}-2 \%$. On the wet side of OMC the axial strain of all the mixtures increases significantly, which indicates that regardless of the amount of FA, compacted mixtures under very wet conditions cannot improve the deformation characteristics of the mixture to minimise settlements under live load and satisfy the required criteria of $2 \%$ maximum axial strain for a base/subbase material (Saberian et al., 2018).

The CBR of CW + FA mixtures with 7, 10 and 13\% FA was evaluated under soaked conditions; the results are shown in Figure 6(c). The samples were compacted at the OMC under modified Proctor effort and then soaked for $4 \mathrm{~d}$ with a $4.5 \mathrm{~kg}$ surcharge. Then, the CBR test was performed as per the Australian standard SA 1289.6.1.1 (SA, 2014). The CBR increases when $7 \% \mathrm{FA}$ is added and then decreases again with larger amounts of FA. Once again this proves that with an optimum amount of FA the strength of the mixture increases due to improved particle interlocking because the FA acts like a void filler. Moreover, the CBR of the mixture with 7\% FA is higher than the minimum required for a subbase in roads, whereas the CBR of all the other mixtures is below the required value.

The $\mathrm{CP}$ of the $\mathrm{CW}+\mathrm{FA}$ mixtures was determined using a modified odometer test. In this test an axial load of $200 \mathrm{kPa}$ was applied and then the sample was flooded with water. The $\mathrm{CP}$ was determined as the change in the void ratio before and after flooding. Figure 6(d) shows that the CP of all the mixtures is well below the maximum value $(1 \%)$ for a base/subbase (Pusadkar and Ramasamy, 2005).

\subsubsection{Evaluating the optimum amount of FA}

Based on the optimum compaction efficiency and the results of CBR, UCS and CP tests, the mixture with 7\% FA was selected as the optimum mixture. In addition to these tests, two-point bending tests and repeated load tests (RLTs) were carried out on the mixture with 7\% FA to further investigate its tensile strength and behaviour under dynamic loading conditions. The tensile strength tests were carried out on the dry side and wet side of the OMC. Figure 7(a) shows how the maximum tensile strength coincides with the OMC (i.e. $6 \%$ ), as determined from the modified Proctor compaction tests. When the water content decreases to OMC-1\% (80\% OMC), the tensile strength also decreases slightly, but there would be a significant drop if the water content decreased to OMC $-2 \%(70 \%$ OMC). Similarly, on the wet side of OMC the tensile strength decreased significantly, even with a $1 \%$ increase in the water content. It was observed that the tensile strain had decreased slightly on the dry side of OMC, whereas the rate of increase in wet conditions was much higher. Therefore, to sustain a higher tensile strength and avoid tensile cracking and cracks propagating onto the surface of the pavement, the mixture must be placed at $\mathrm{OMC}$ or slightly drier than OMC (>80\% OMC). Wet conditions must be avoided because they inhibit compaction, induce higher axial and tensile strains, and reduce the tensile strength of the mixture.

RLTs were carried out as specified by Austroads (2007). These tests consist of five separate stages of 10000 cycles per stage; 


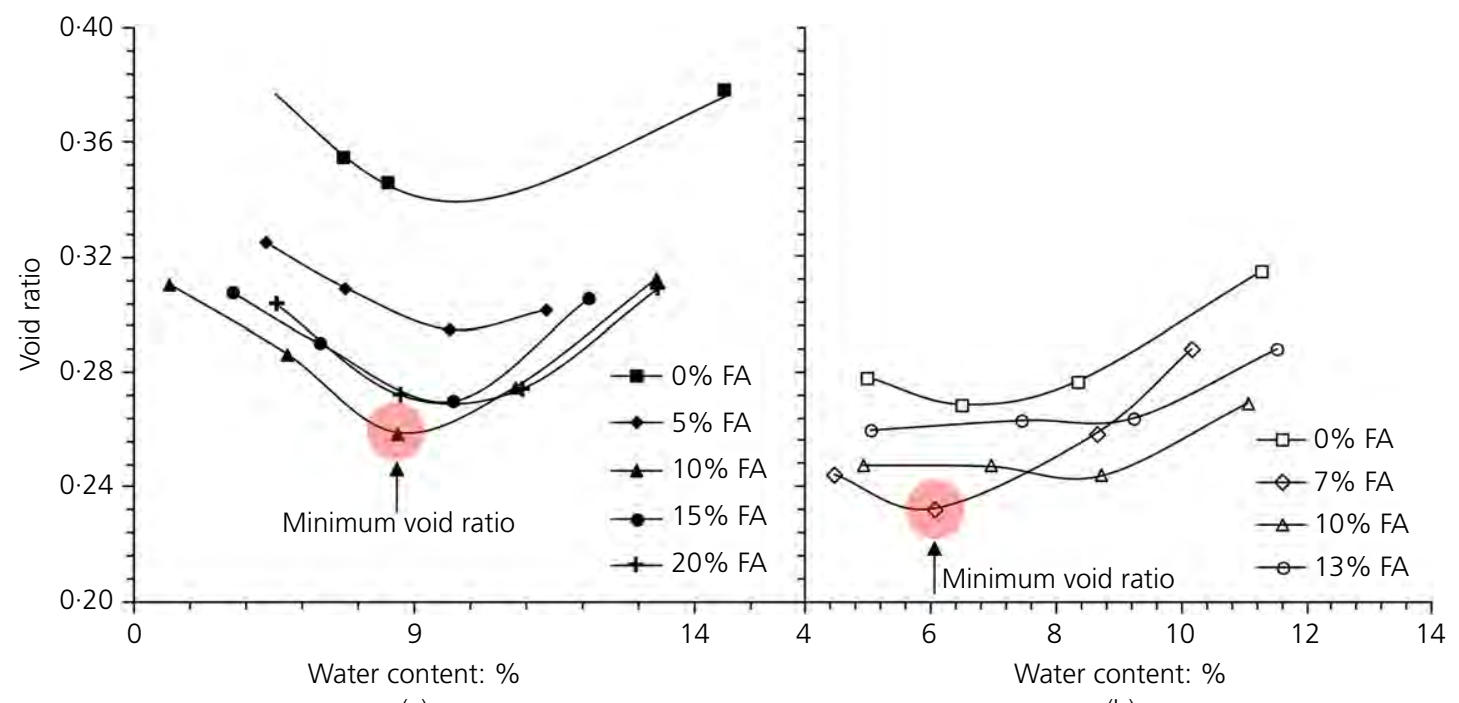

(a)

(b)

Figure 5. Compaction characteristics of CW + FA at (a) standard Proctor and (b) modified Proctor

Table 1. Sample properties for the UCS tests

\begin{tabular}{|lcc|}
\hline \multirow{2}{*}{ Test } & \multicolumn{2}{c|}{ UCS } \\
\hline \multirow{2}{*}{ FA content: \% } & Moisture content: \% & Dry density: $\mathbf{g} / \mathrm{cm}^{3}$ \\
\hline 0 & 4.98 & 1.76 \\
& 6.50 & 1.77 \\
& 8.34 & 1.76 \\
7 & 11.26 & 1.71 \\
& 4.46 & 1.79 \\
& 6.06 & 1.81 \\
& 8.64 & 1.77 \\
10 & 10.17 & 1.73 \\
& 4.63 & 1.77 \\
& 7.09 & 1.77 \\
13 & 8.97 & 1.78 \\
& 10.67 & 1.74 \\
& 5.04 & 1.75 \\
& 7.45 & 1.75 \\
& 9.23 & 1.75 \\
\end{tabular}

the cyclic deviator stress was increased by $100 \mathrm{kPa}$ at each stage to mimic different loading conditions at the level of the subbase and base layer in roads. Figures 7(b) and 7(c) show the permanent axial strain and resilient modulus at the end of each stage under four dry-back conditions. When tested at $\mathrm{OMC}$, the strain accumulates at an increasing rate, with an increasing cyclic stress, while the frictional failure commences at the beginning of the fourth stage with a load greater than $350 \mathrm{kPa}$. When the load is below $350 \mathrm{kPa}$, the axial strain decreases with a decreasing water content up to a dry back of $80 \% \mathrm{OMC}$, and then it increases again with a further dry back to $70 \%$ OMC. At a greater load (i.e. $>350 \mathrm{kPa}$ ), the minimum axial strain corresponds to $80 \% \mathrm{OMC}$, whereas the mixture at $90 \%$ OMC exhibits frictional failure, as noted by an increasing rate of strain accumulation. The resilient modulus (Figure 7(c)) increases as the cyclic deviator stress increases due to the densification experiences at each loading stage; it also increases as the water content decreases. At $80 \%$ OMC, the mixture could sustain a resilient modulus ranging from 100 to $140 \mathrm{MPa}$ for cyclic loads of 150 and $550 \mathrm{kPa}$, respectively. The RLTs show that the mixture is good enough for a subbase with $80 \%$ OMC dry back, but it can only be used as a base if the live loads are less than $350 \mathrm{kPa}$ - that is, for roads carrying light traffic.

\section{Role of recycled rubber for railways}

This section mainly focuses on several innovative ways to improve the rail track performance using recycled rubber products, including (a) developing a SEAL for railway subballast by adding $\mathrm{RC}$ in mining waste (i.e. SFS and $\mathrm{CW}$ ); (b) using recycled waste tyre cell to reinforce the railway capping layer; and (c) installing USP or UBM to reduce the track displacement and ballast degradation. The large-scale process simulation primordial testing apparatus (PSPTA) at the UOW was used to examine the performance of different methods, and the schematic illustration of each method is shown in Figures 8(b)-8(d).

\subsection{SEAL for subballast using SFS $+\mathrm{CW}+\mathrm{RC}$ mixtures} Indraratna et al. (2017a) extended the use of mining waste (SFS and CW) by adding RC to mixtures of SFS + CW to develop a SEAL for railway subballast. They found that adding rubber $R_{\mathrm{b}} \geq 10 \%$ (by weight) to $\mathrm{SFS}+\mathrm{CW}$ mixtures having SFS:CW $=7: 3$ (the optimal blending ratio, by weight), these waste mixtures of SFS $+\mathrm{CW}+\mathrm{RC}$ can provide a comparable shear strength to traditional subballast, but without inducing any risk of the SFS swelling and particle breakage of CW (Indraratna et al., 2017a; Qi et al., 2018a, 2019a, 2019b). To better understand the damping property and energy-absorption 


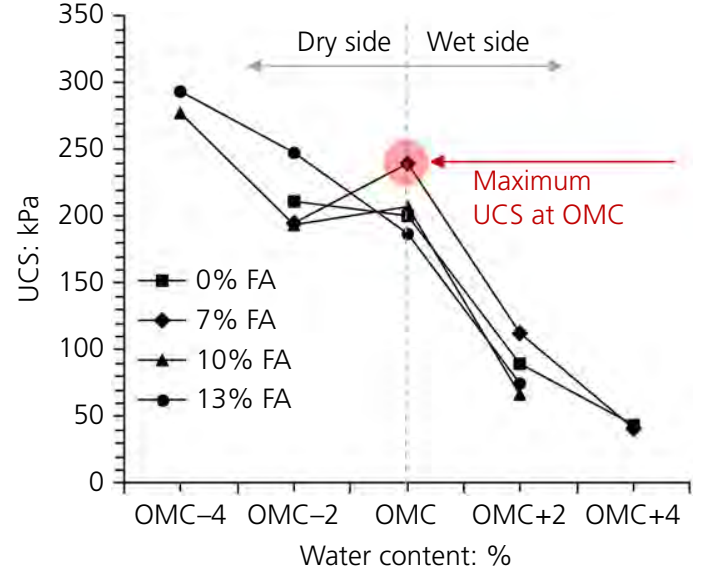

(a)

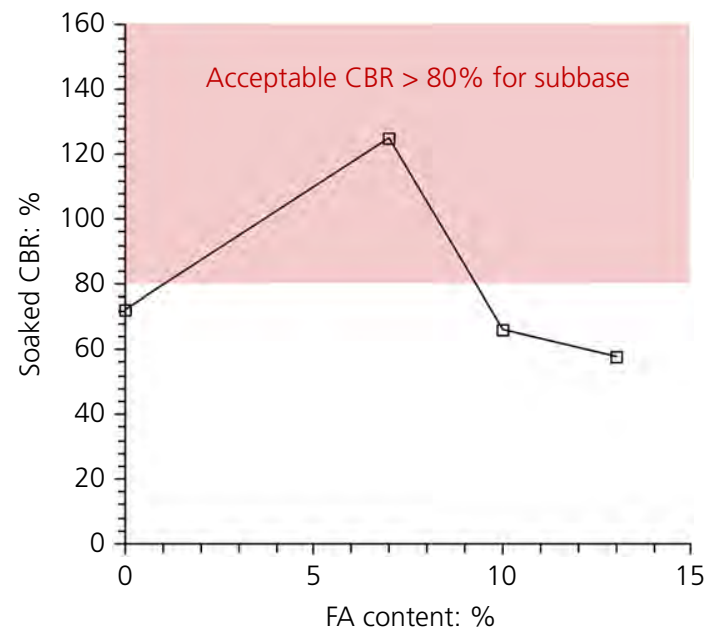

(c)

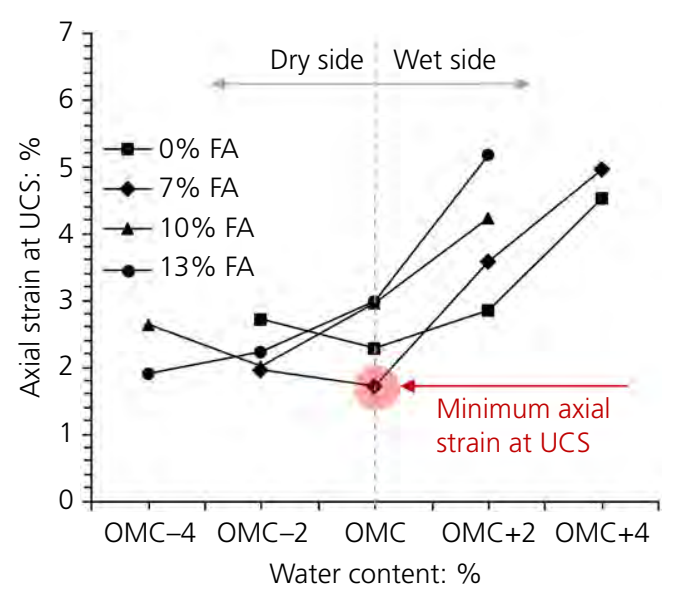

(b)

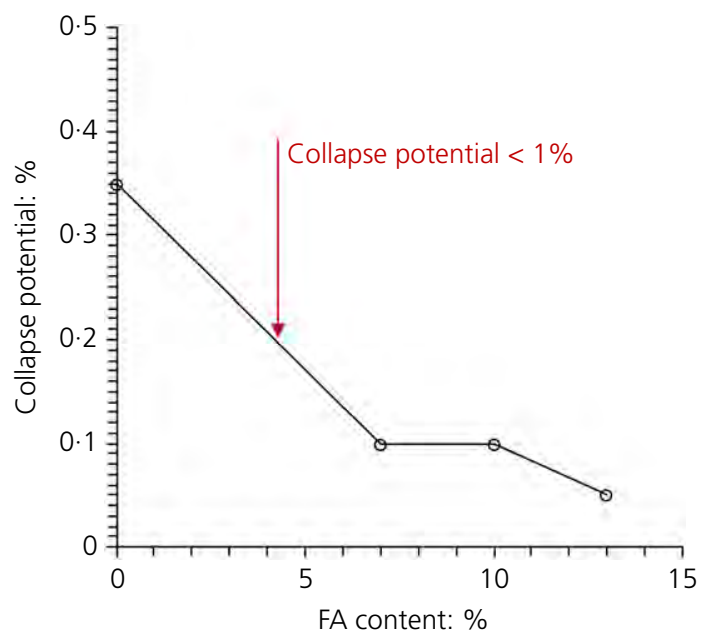

(d)

Figure 6. (a) UCS, (b) maximum axial strain, (c) soaked CBR and (d) CP of CW + FA mixtures (source: modified after Wang et al. (2019))

concept of the SFS + CW + RC mixture by adding rubber, a series of small-scale cyclic loading triaxial tests were carried out on these waste mixtures and a large-scale physical model was proposed to verify the enhanced energy-absorbing capacity after adding SEAL to a track.

\subsubsection{Materials and cyclic testing programme}

The source materials for SFS and CW are the same as those mentioned in Section 2, whereas the RC shredded from waste tyres provided by Tyre Crumbs Australia were of four sizes $(0-2 \cdot 3,0 \cdot 3-3,4-7$ and $8-15 \mathrm{~mm})$. The PSD curves of RC, SFS and CW are shown in Figure 9(a). All the waste materials were sieved and separated according to their size ranges. When preparing the samples $(50 \mathrm{~mm}$ in diameter and $100 \mathrm{~mm}$ high) for the cyclic triaxial test, all the mixtures were prepared following the same target PSD (see Figure 9(b)) by adding the exact weight of each material (i.e. SFS, CW and RC) according to the different size ranges. The target PSD for the waste mixtures is comparable with traditional subballast materials tested in previous studies - for example, Trani and Indraratna (2010),
Radampola et al. (2008) and Kabir et al. (2006). The optimal blending ratio of SFS:CW=7:3 was used with varying amounts of RC contents $\left(R_{\mathrm{b}}=0,10,20,30\right.$ and $\left.40 \%\right)$. Each $\mathrm{SFS}+\mathrm{CW}+\mathrm{RC}$ mixture was compacted to around $95 \%$ of its maximum dry density (MDD) after being mixed with its optimum water content.

The consolidated drained cyclic triaxial test was in accordance with ASTM D5311/D5311M (ASTM, 2013). Three confining pressures $\left(\sigma_{3}^{\prime}=10,40\right.$ and $\left.70 \mathrm{kPa}\right)$ and the cyclic stress ratio (CSR $\left.=q_{\text {cyc,max }} / 2 \sigma_{3}^{\prime}=0 \cdot 8\right)$ were used to simulate field conditions. The cyclic loading test was completed up to 50000 cycles at a frequency of $5 \mathrm{~Hz}$. The details of this test procedure can be found in Indraratna et al. (2017a) and Qi et al. (2018b).

\subsubsection{Damping property and the energy dissipation concept}

Damping is the ability of a material to dissipate energy when subjected to a dynamic load. The damping ratio $(D)$ is the key parameter needed to evaluate the damping capacity of waste 


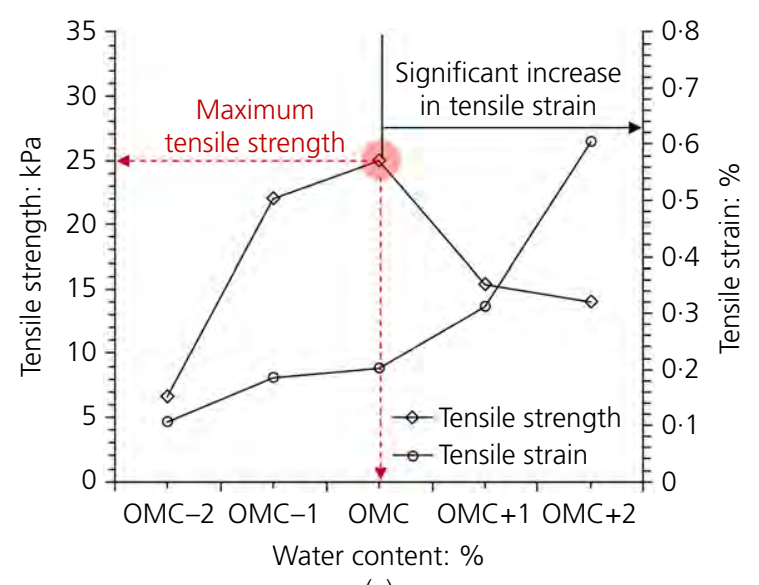

(a)

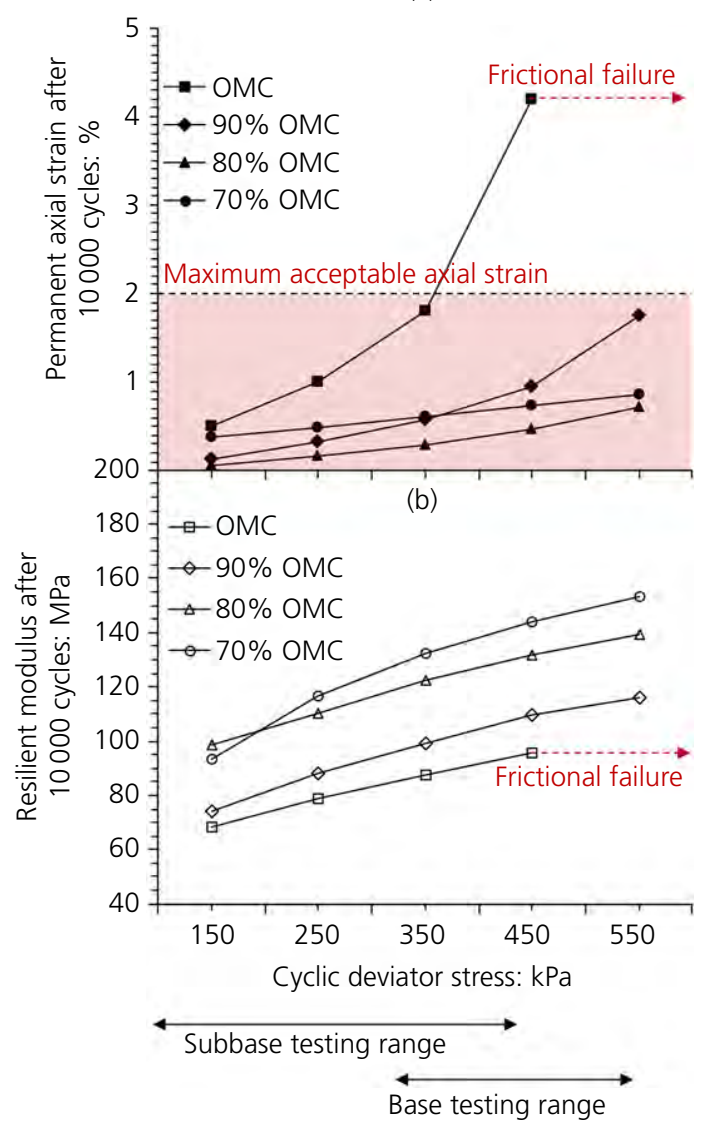

(c)

Figure 7. (a) Tensile strength, (b) permanent deformation and (c) resilient modulus of CW + FA mixture with 7\% FA at different dry-back conditions

mixtures, and it can be calculated by using the typical stress-strain hysteresis loop shown in Figure 10(a). The total amount of energy dissipated in one loading cycle $(E)$ can be represented by the area of the hysteresis loop (Figure 10(a)). The typical stress-strain hysteresis loop of SFS + CW + RC mixtures with different RC contents is shown in Figure 10(b). It shows that as $R_{\mathrm{b}}$ increases, the hysteresis loop becomes bigger, indicating that more energy has dissipated, and at the same loading cycle, more rubber in the waste mixture causes more vertical strain due to the highly deformable behaviour of rubber materials.

Figure $10(\mathrm{c})$ shows $D$ and $E$ of the waste mixture in variation with the loading cycles $(N)$. As expected, the damping ratio and dissipated energy increase as $R_{\mathrm{b}}$ increases. Note that the $D$ and $E$ of the $\mathrm{SFS}+\mathrm{CW}+\mathrm{RC}$ mixture having $R_{\mathrm{b}}=0 \%$ are very stable as $N$ changes, whereas the $D$ and $E$ of waste mixtures with $R_{\mathrm{b}} \geq 10 \%$ reduce as $N$ increases and then stabilise at around $N=10000$ (Figure 10(c)). Note also that when an RC of $10 \%$ is added to the waste mixture, $D$ increases dramatically, whereas when more RC is included the increase rate in $D$ actually decreases. This is because after adding a certain amount of $\mathrm{RC}(>10 \%)$, the skeleton of the waste mixture is governed by $\mathrm{RC}$ particles, so the mixture tends to behave more like rubber, as suggested by Qi et al. (2018b). The influence of $\sigma_{3}^{\prime}$ on $D$ and $E$ is shown in Figure 10(d), where the $\mathrm{SFS}+\mathrm{CW}+\mathrm{RC}$ mixture with $R_{\mathrm{b}}=10 \%$ is used as an example. When $\sigma_{3}^{\prime}$ increases, the damping ratio decreases but more energy is dissipated, thus indicating that the efficiency of dissipating energy decreases.

It is assumed that under a given track load the total energy input of the track substructure (ballast, subballast and subgrade) is a certain amount. The total energy absorbed or accumulated by a track system will be converted to elastic energy by way of elastic strain and the dissipated energy (particle breakage, plastic deformation, heat, sound etc.). By taking the SEAL as an example, when $R_{\mathrm{b}}$ increases, the dissipated energy increases (Figure 10(c)) and the elastic energy also increases, as shown by Qi et al. (2018b), and thereby the total absorbed energy increases due to the addition of RC. Therefore, by increasing the energy-absorbing capacity of the subballast layer using SEAL, the energy transferred to the ballast and the subgrade can further decrease, which in turn reduces ballast breakage and associated deformation.

\subsubsection{Physical modelling}

To verify the energy dissipation concept and examine the performance of a track using SEAL as subballast, a physical model was developed and tested using the large-scale PSPTA shown in Figure 8(a). The PSPTA testing cell had an area of $600 \times 800 \mathrm{~mm}$ and is $600 \mathrm{~mm}$ in depth. The physical model consisted of three layers (Figure $8(\mathrm{~b})$ ) - that is, the ballast layer (200 mm thick), the subballast layer (150 mm thick) and the subgrade layer (100 mm thick). A $150 \mathrm{~mm}$ thick concrete sleeper was placed on top of the test specimen, and around it was filled with the shoulder ballast. The ballast and subgrade materials were from a local quarry near UOW; their PSD is shown in Figure 9(a). While preparing the test specimen, the PSD of ballast was obtained according to the Standard Australia (SA, 2015), and the ballast and subgrade materials were compacted to field conditions. The SEAL mixture $(\mathrm{SFS}+\mathrm{CW}+\mathrm{RC})$ was used as subballast instead of traditional subballast materials. The target PSD of the SEAL mixture for 


\section{Offprint provided courtesy of www.icevirtuallibrary.com Author copy for personal use, not for distribution}

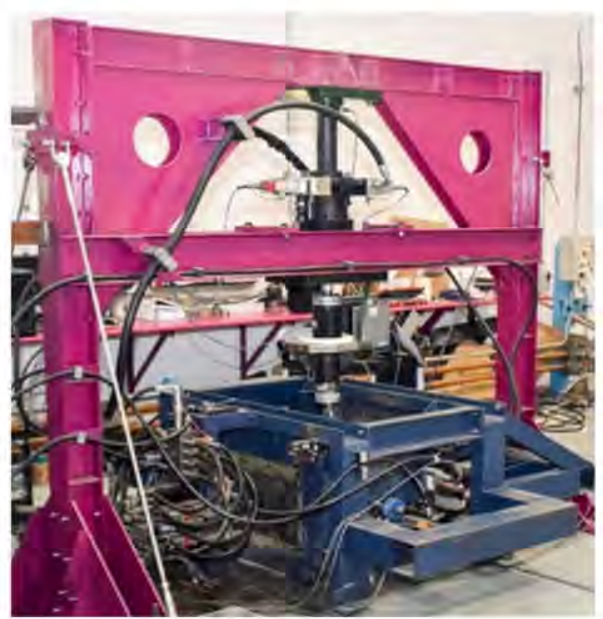

(a)

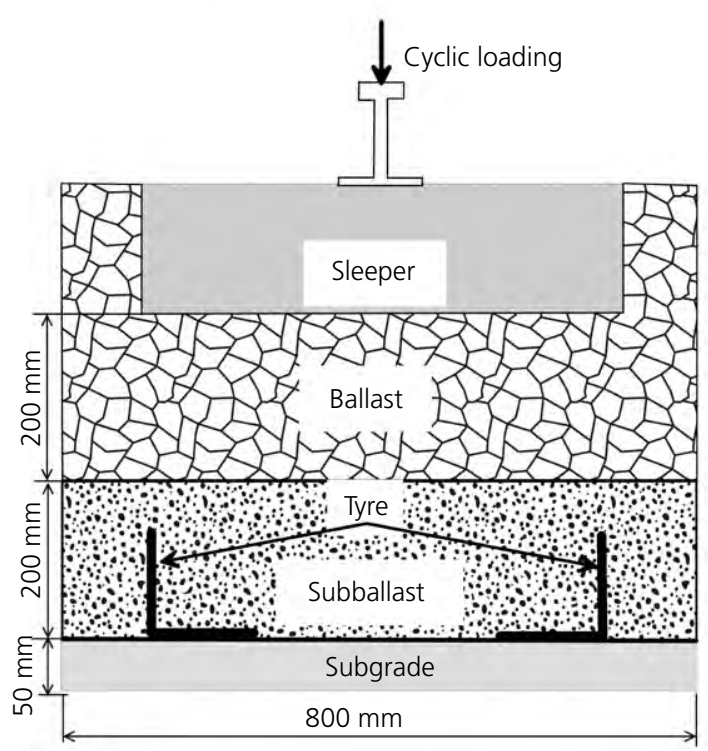

(c)

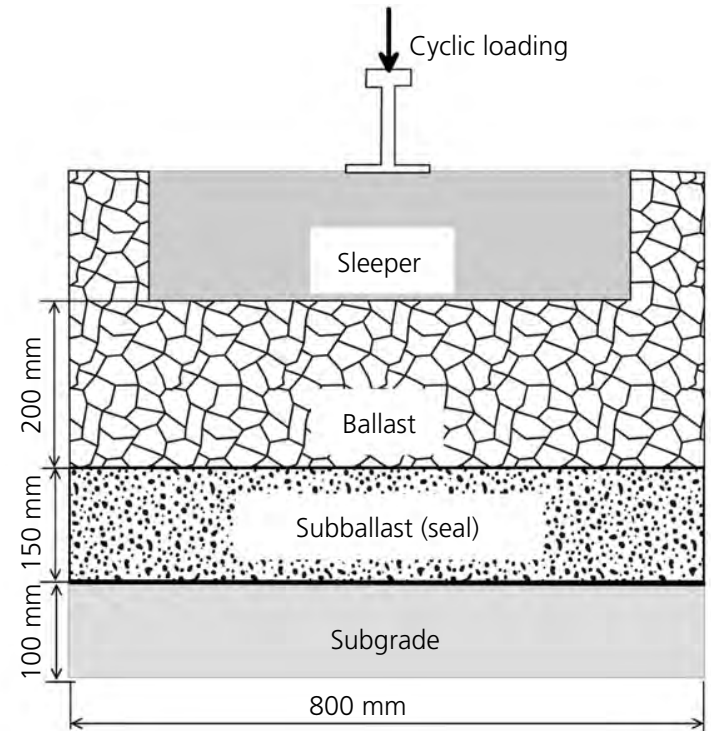

(b)

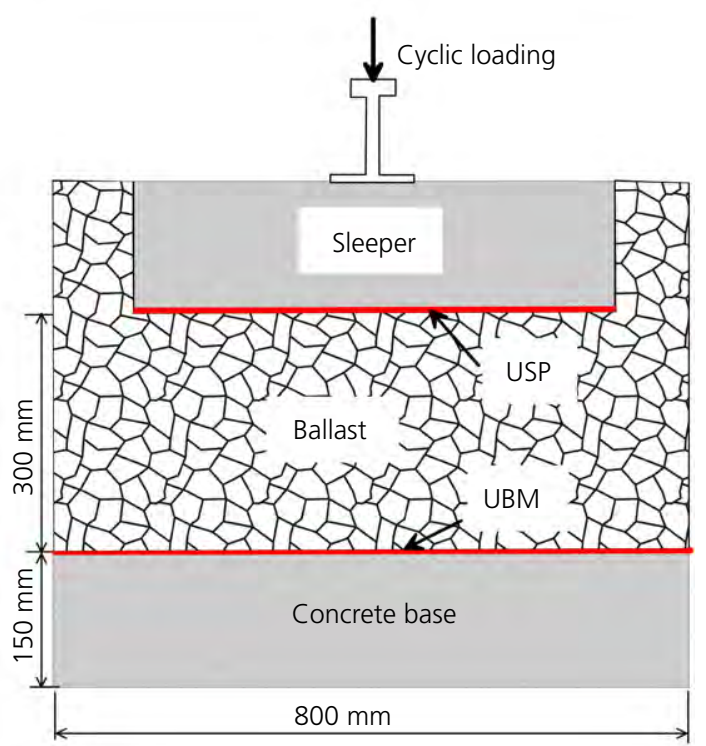

(d)

Figure 8. (a) PSPTA at the UOW, and schematic illustration of; (b) the physical model with SEAL; (c) the prismoidal triaxial box reinforced with a recycled tyre cell; and (d) the prismoidal triaxial box with rubber mats

the large-scale cubical triaxial test is shown in Figure 9(b). Five large-scale triaxial tests were carried out, and in each test the amount of $\mathrm{RC}(0,10,20,30$ and $40 \%)$ in the SEAL was changed beforehand. A maximum cyclic vertical stress of $230 \mathrm{kPa}$ and a loading frequency of $15 \mathrm{~Hz}$ was used to simulate a train with a $25 \mathrm{t}$ axle load with a speed of $110 \mathrm{~km} / \mathrm{h}$ (Indraratna et al., 2014; Jayasuriya et al., 2019; Navaratnarajah and Indraratna, 2017). A lateral confining pressure $\sigma_{3}^{\prime}=15 \mathrm{kPa}$ was applied in the transverse direction of the track to simulate the pressure provided by the crib and shoulder ballast according to real track conditions (Navaratnarajah et al., 2018). After each test, the ballast was sieved to examine the particle breakage. During these tests, only the specimen with $40 \%$ RC failed at around 1500 cycles due to severe vibration and settlement, all the other tests were completed up to 500000 cycles.

To evaluate the particle degradation of ballast during cyclic loading, the ballast breakage index (BBI) initially proposed by Indraratna et al. (2005) was used; the BBI can be calculated based on the PSD before and after the test; the details are shown in Figure 11(a). The BBI of the test specimen with different amounts of RC is shown in Figure 11(b). As expected, the addition of RC in SEAL significantly reduces the ballast particle breakage more than the one without RC, but when more $\mathrm{RC}$ is included in SEAL, there is no significant reduction in $\mathrm{BBI}$ and the value for the specimen with $20 \% \mathrm{RC}$ 


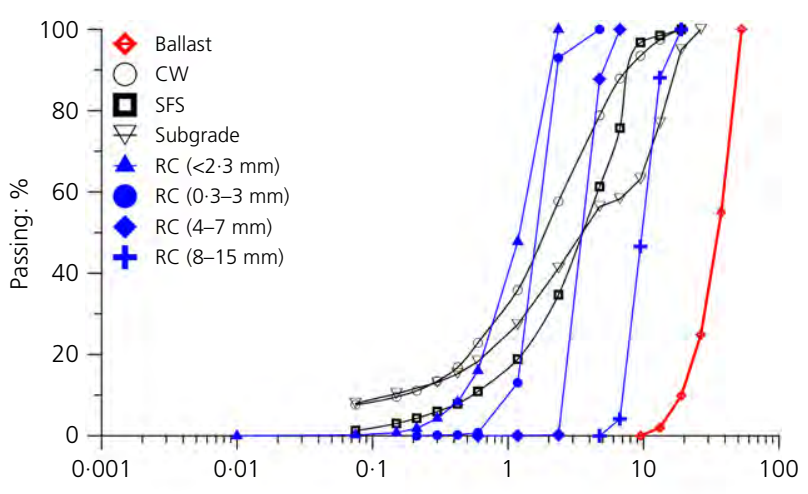

(a)

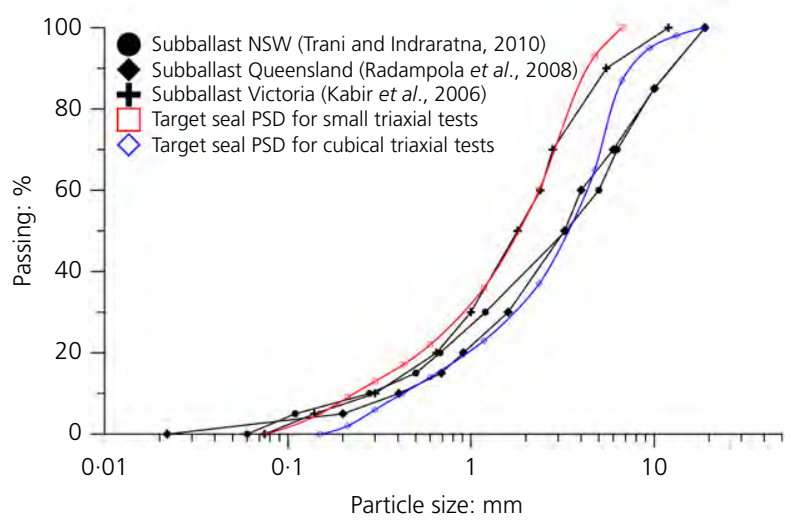

(b)

Figure 9. (a) PSD for ballast, subgrade and waste materials; (b) PSD for traditional subballast and target SEAL PSD for small and cubical triaxial tests

is even higher; this is probably due to the vibration caused by the rubbery behaviour of the SEAL, as explained earlier. The plastic vertical strain $\varepsilon_{1}$ of the track specimen is shown in Figure 11(c), where $\varepsilon_{1}$ of the track specimen increases as $R_{\mathrm{b}}$ increases in the SEAL. Note that the failed test specimen with $40 \% \mathrm{RC}$ had a plastic axial strain of almost $10 \%$ even after 1500 cycles. This indicates that too much RC $(\geq 40 \%)$ can induce track failure due to excessive settlement and vibration. Compared to the traditional track specimen in the previous study that was tested by Jayasuriya et al. (2019) under the same loading conditions, except for the specimen with $0 \% \mathrm{RC}$, all the specimens with SEAL having $R_{\mathrm{b}} \geq 10 \%$ could reduce the BBI by $40-60 \%$ with acceptable vertical deformation. Therefore it is recommended that $10 \%$ of RC should be added to the SEAL because it enhances track performance with less ballast breakage and track settlement.

\subsection{SEAL for subballast using $\mathrm{CW}+\mathrm{RC}$ mixtures}

\subsubsection{Strength and deformation}

An alternative method for developing a SEAL, using CW and $\mathrm{RC}$ only, is also possible for the subballast/capping layer; however, since CW is weaker than SFS, removing SFS from the blend would affect the strength and deformation of the mixture. Compaction tests and monotonic triaxial tests were carried out on four CW + RC mixtures with $0,5,10$ and $15 \%$ rubber to evaluate its effect on the geotechnical behaviour of a CW + RC mixture (Indraratna et al., 2019b). Indraratna et al. (2019b) proved that the mixture can be compacted to an acceptable void ratio by increasing the compaction energy without inducing excessive breakage, so triaxial tests were then carried out under three confining pressures to mimic different field conditions (i.e. 25,50 and $75 \mathrm{kPa}$ ). All the mixtures were compacted to the same void ratio to examine how the amount of rubber would affect the stress-strain response.

Figure 12(a) shows the stress-strain relationship of $\mathrm{CW}+\mathrm{RC}$ mixtures at a confining pressure of $50 \mathrm{kPa}$. It is noted that the inclusion of RC improves the ductility of the material. Ductility prevents tensile cracking and sudden and brittle failure when a mixture is subjected to a long life cycle and when it reaches a state of fatigue. For the CW + SFS + RC mixture tested by Indraratna et al. (2017a), the peak deviator stress decreases as the amount of rubber increases; however, Figure 12(b) shows that the peak deviator stress of all the mixtures is greater than the maximum axial stress expected at the level of the subballast/capping layer.

The inclusion of rubber particles induces higher deformation under the same stress because the rubber compresses and becomes deformed. The axial strain at the peak deviator stress plotted in Figure 12(c) shows that the axial strain increases as the amount of rubber increases. The maximum allowable settlement of the subballast/capping layer is $2 \%$. In Figure 12(d), the deviator stress that corresponds to an axial strain of $2 \%$ is plotted. For an amount of $\mathrm{RC} \leq 10 \%$ and the confining pressure usually observed in practice (i.e. $40-50 \mathrm{kPa}$ ), the mixture can sustain a stress that is higher than the expected stress at the level of the subballast/capping layer with an axial deformation of $2 \%$. This indicates that the inclusion of rubber does not induce excessive settlement if the amount of $\mathrm{RC}$ is less than $10 \%$.

\subsubsection{Energy absorption}

The main reason for using recycled rubber in infrastructure sublayers is to minimise particle degradation and increase the energy-absorbing potential of the material. Figure 13 shows the breakage index (BI) and the energy-absorbing potential of $\mathrm{CW}+\mathrm{RC}$ mixtures. The $\mathrm{BI}$ was determined after compaction based on the method proposed by Indraratna et al. (2005) and the energy-absorbing capacity was evaluated based on the maximum work absorbed by the mixture up to the point of failure (Indraratna et al., 2019b). Figure 13(a) shows that the BI decreases by approximately $50 \%$ when $10 \%$ of RC is added, after which there is no significant decrease in breakage. This indicates that an amount of rubber of more than $10 \%$ is unnecessary because it only induces higher axial settlement without any further reduction in degradation. The energyabsorbing potential shown in Figure 13(b) indicates that the capacity of the mixture to absorb energy increases as the 


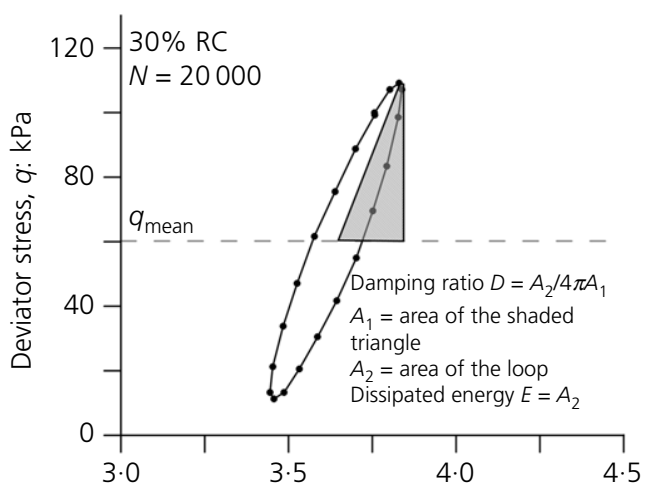

(a)

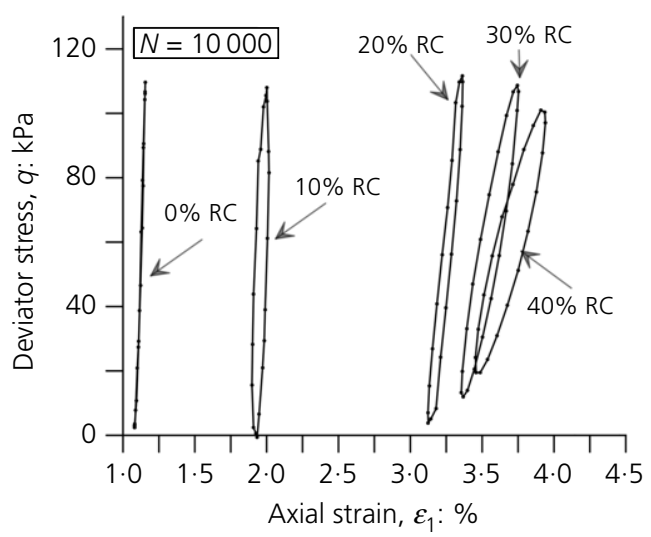

(b)

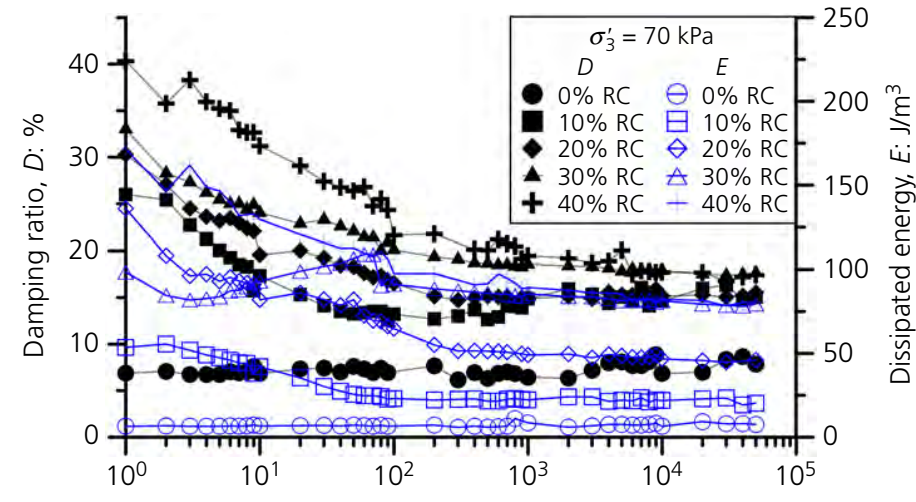

(c)

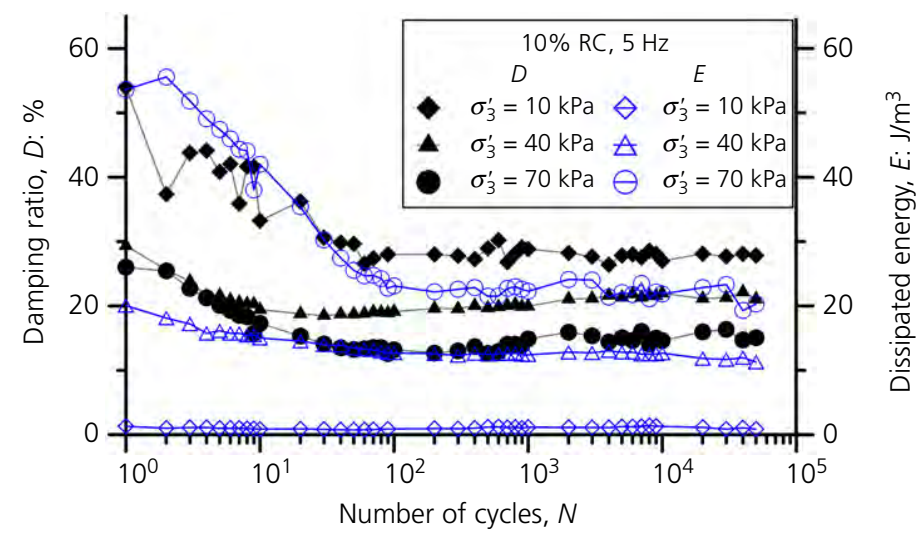

(d)

Figure 10. (a) Definition of damping ratio and dissipated energy; (b) hysteresis loops of the waste mixture having different RC contents, and damping ratio and dissipated energy of (c) SFS $+\mathrm{CW}+\mathrm{RC}$ mixtures having different RC contents under $\sigma_{3}^{\prime}=70 \mathrm{kPa}$ and (d) $\mathrm{SFS}+\mathrm{CW}+\mathrm{RC}$ mixtures having $10 \% \mathrm{RC}$ under different $\sigma_{3}^{\prime}$

amount of rubber increases. This increase is more evident at higher confining pressures due to an increase in the compressibility of rubber. An energy-absorbing layer is of great benefit in corridors that generate vibration, such as railways. Previous studies showed there was much less vibration when a layer of rubber was introduced into the track (Cho et al., 2007). Similarly, a SEAL matrix helps to attenuate noise and vibration so there is less disturbance in the surrounding environment at sites where a railway track is very close to residential or commercial areas.

\subsection{Waste tyre cell-reinforced capping layer for heavy-haul loading}

\subsubsection{Materials and test loading conditions}

An innovative method for confining the capping layer (subballast) using recycled tyre cells has been proposed by Indraratna et al. (2017c) and Sun et al. (2019). The aim is to reduce particle movement and ballast degradation, and increase the stability and resiliency of track infrastructure. Large-scale cyclic cubical triaxial tests using PSPTA were carried out to evaluate a capping layer confined with tyre cells; this large-scale triaxial sample contained a ballast layer, a capping layer and a subgrade layer (Figure 8(c)). The ballast and capping layers are crushed basalt (latite) with particle sizes ranging from 2.36 to $53 \mathrm{~mm}$ and 0.075 to $19 \mathrm{~mm}$, respectively. The bottom layer is a $50 \mathrm{~mm}$ thick subgrade layer. The cyclic loading test proceeded under two different conditions, a traditional track specimen confined with and without a recycled tyre cell. One sidewall of the recycled tyre was removed and the tyre was filled with traditional capping materials (i.e. crushed basalt). A woven geotextile was installed at the interface of the capping layer and the structural fill to serve as a separator.

The cyclic loading tests carried out at $15 \mathrm{~Hz}$, a maximum axial stress $\sigma_{1 \text { cyc, } \max }^{\prime}=385 \mathrm{kPa}$ and a minimum axial stress $\sigma_{\text {cyc,min }}^{\prime}=15 \mathrm{kPa}$ were applied to simulate a heavy-haul train with an axle load of $40 \mathrm{t}$ (Jeffs and Tew, 1991). Each cyclic loading test consisted of 500000 cycles, after which the ballast was sieved to determine the extent of degradation.

\subsubsection{Test results}

Figure 14(a) shows the results of the cubical triaxial test in terms of the lateral and vertical deformation of the specimens 


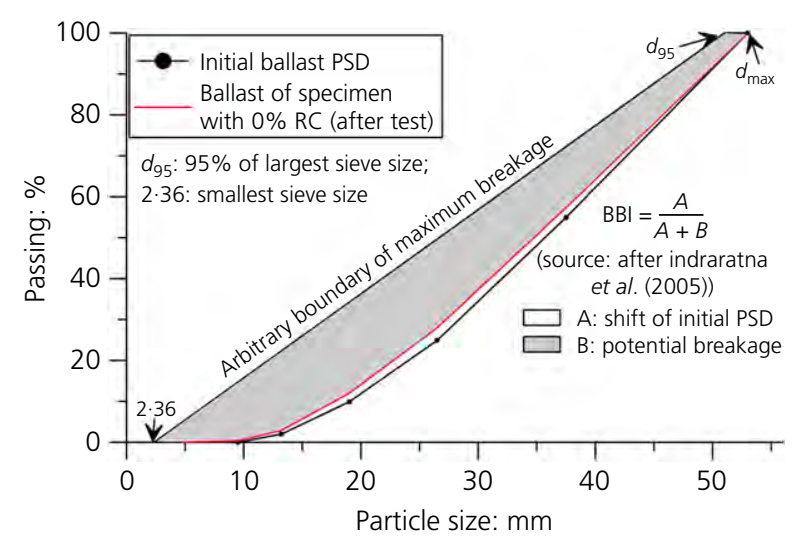

(a)

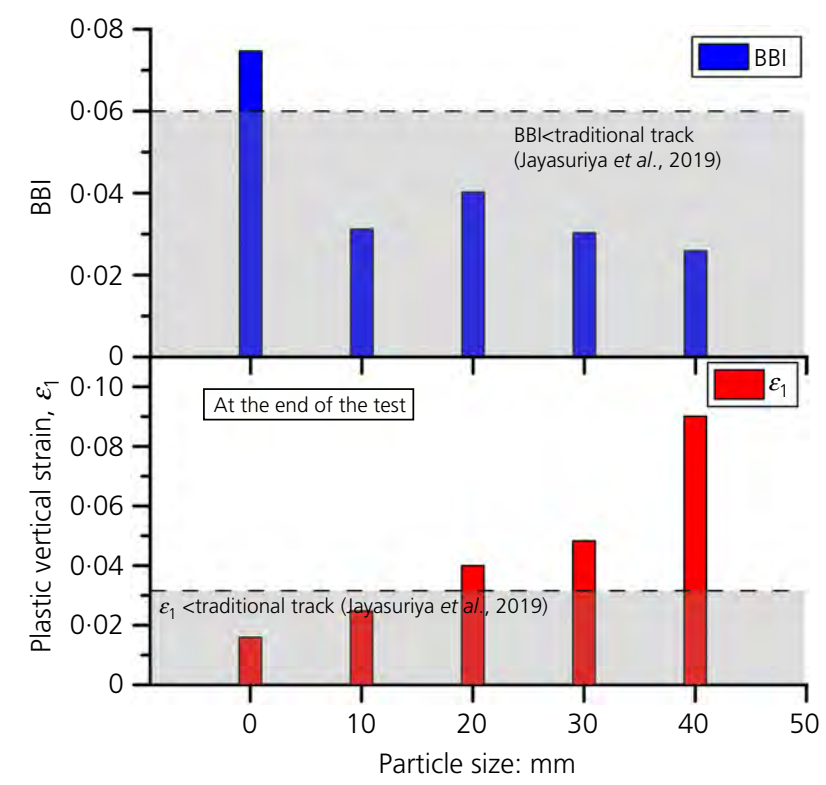

(b)

Figure 11. (a) Definition of BBl; cubical triaxial test result of (b) BBI and (c) plastic vertical strain

where lateral displacement without a tyre cell increases rapidly at the beginning of the test and then stabilises around $N=100000$ cycles. As expected, there is a dramatic reduction in the lateral displacement of the specimen with a tyre cell because the particles are confined and therefore tend to contract more. The vertical settlement develops rapidly during the first thousands of loading cycles and then gradually stabilises after 100000 cycles. It is noteworthy that the specimen reinforced with a tyre cell experiences a greater reduction in the vertical displacement (around 10-12 $\mathrm{mm}$ ) than the specimen without a tyre cell. Overall, these test results indicate that the additional confinement provided by a tyre cell can reduce track settlement and lateral displacement.

The damping ratio $(D)$ and dissipated energy $(E)$ of the test specimen confined with and without a tyre cell are shown in Figure 14(b). The tests show that when a track is confined by a tyre cell the damping property is enhanced and the dissipated energy increases. When the test begins, the $D$ and $E$ decrease as the number of loading cycles increase due to the high dissipation of energy caused by plastic sliding and particle breakage, but when there are more than 10000 loading cycles the $D$ and $E$ are almost constant because the granular mass becomes dense and stable.

Ballast could experience significant degradation during longterm service due to repeated loading (Indraratna et al., 2011), but since tyre cells have a higher damping property they can reduce ballast degradation. The PSD of the ballast before and after the test, and the BBI values of specimens with and without a tyre cell, are shown in Figure 15; here the PSD curves indicate that the biggest change in the size of ballast took place in the $37.5 \mathrm{~mm}$ sieve. The BBI of the specimen confined with a tyre cell is almost $70 \%$ less than the specimen without a tyre cell. This result suggests that a ballast layer could become more durable if the capping layer is reinforced by energy-absorbing tyre cells, a result that would reduce the amount of aggregates taken from quarries.

\subsection{Using rubber mats/pats to improve the performance of track with stiff subgrade}

\subsubsection{USP and UBM testing programme}

A series of tests to investigate the effect of USP and UBM for rail track built on a stiff subgrade, such as tunnels and bridges, was carried out using PSPTA. The test specimen contained two layers: (a) a $300 \mathrm{~mm}$ thick ballast layer and (b) a $150 \mathrm{~mm}$ thick concrete base to simulate a rail track on a stiff subgrade. The position of the USP and UBM is also shown in Figure $8(\mathrm{~d})$. The ballast material tested was the same as that mentioned in the previous section. The USP and UBM were manufactured from recycled waste tyres. The rubber mats/pats were made by encapsulating waste rubber granulates in a polyurethane elastomer compound. The USP and UBM were $200 \times 800 \times 10 \mathrm{~mm}$ thick and $600 \times 800 \times 10 \mathrm{~mm}$ thick, respectively. Cubical triaxial tests were conducted with USP, with UBM, and without any rubber inclusions. The maximum vertical stress at the sleeper-ballast interface was $230 \mathrm{kPa}$ to simulate a train with a $25 \mathrm{t}$ axle load. The influence of frequency was captured by varying the loading frequency (i.e. 15, 20 and $25 \mathrm{~Hz}$ ). Each test was carried out up to 500000 cycles, after which the ballast was sieved to check the particle degradation.

\subsubsection{Deformation, damping property and ballast degradation}

The settlement and lateral displacement of the test specimen without rubber inclusions, and with USP or UBM under different loading frequencies are shown in Figures 16(a) and 16(b). Since the concrete base is regarded as rigid, the deformation recorded here only refers to the ballast layer. The test results indicate that the ballast quickly deforms vertically and laterally up to around 10000 cycles and remains relatively 


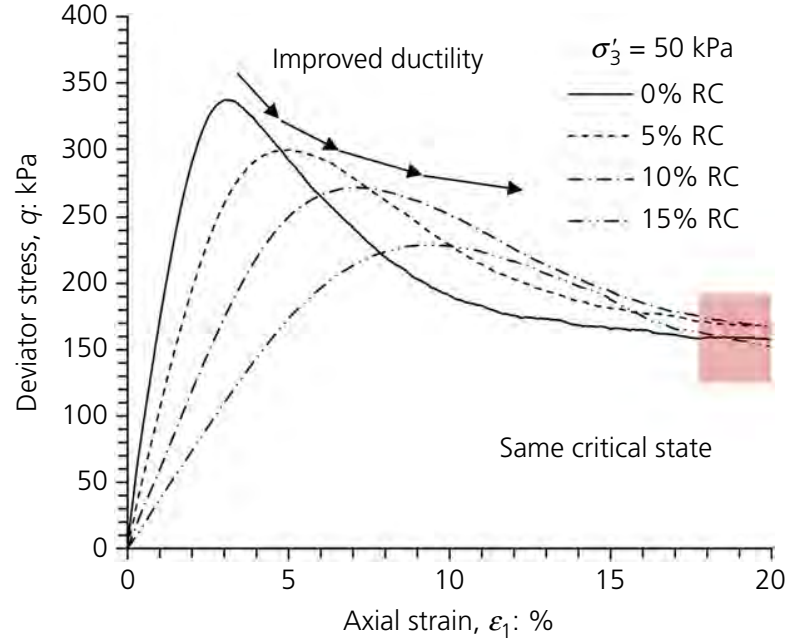

(a)

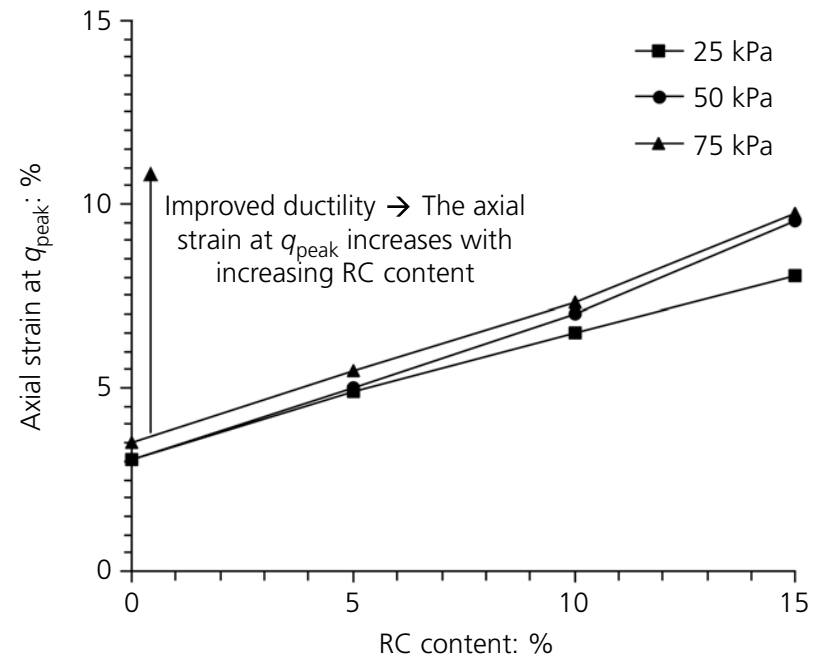

(c)

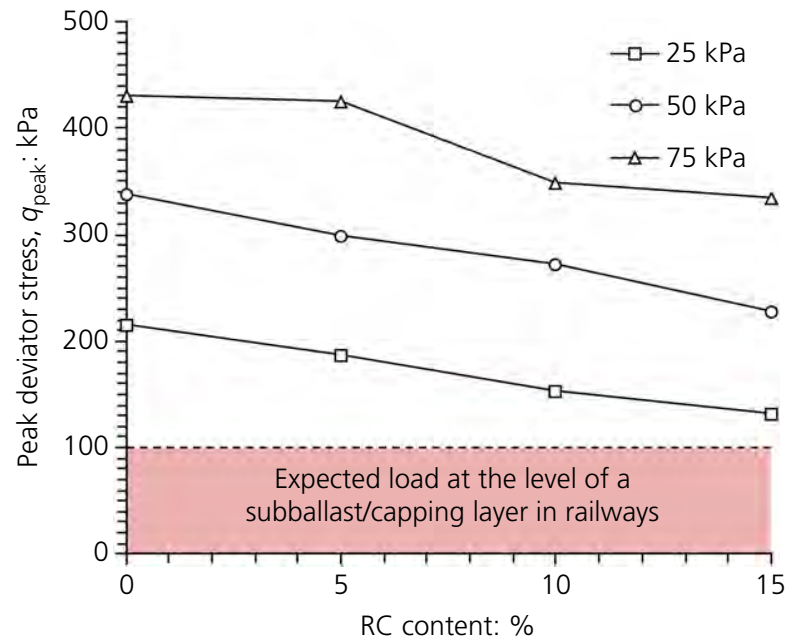

(b)

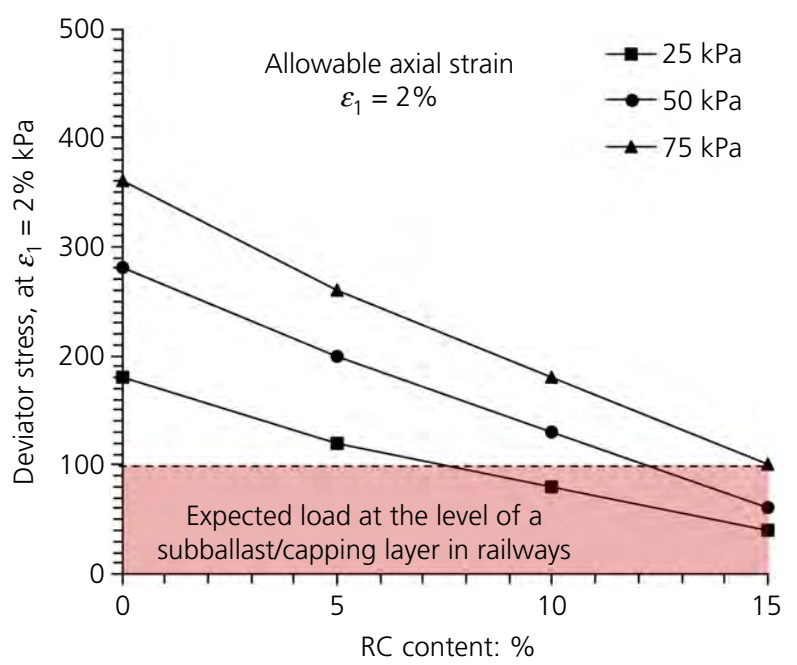

(d)

Figure 12. (a) Stress-strain curve at a confining pressure of $50 \mathrm{kPa}$ and (b) peak deviator stress at different confining pressures; (c) axial strain at $q_{\text {peak }}$ and (d) $q_{\text {peak }}$ at $2 \%$ axial strain of $C W+R C$ mixtures

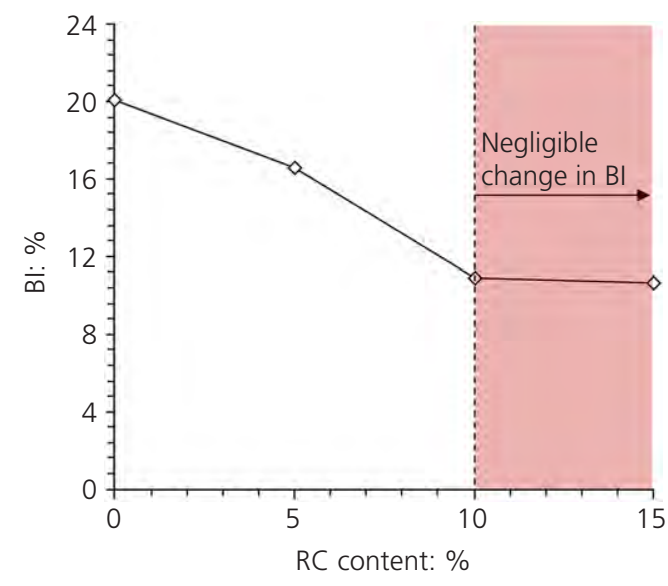

(a)

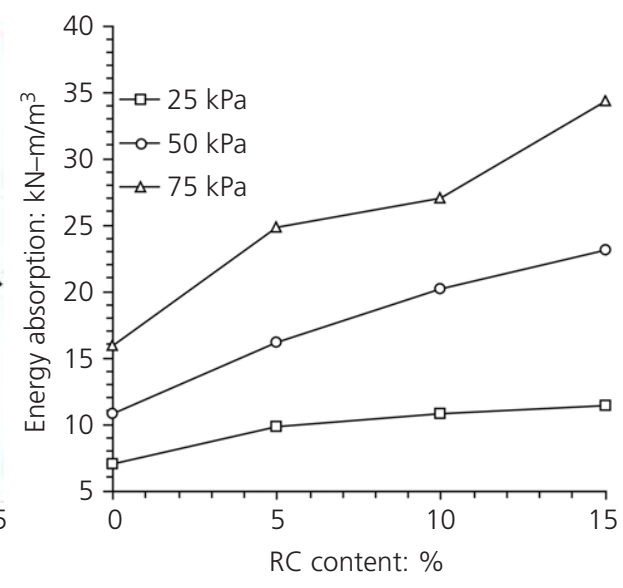

(b)

Figure 13. (a) BI and (b) energy-absorption potential of CW + RC mixtures 


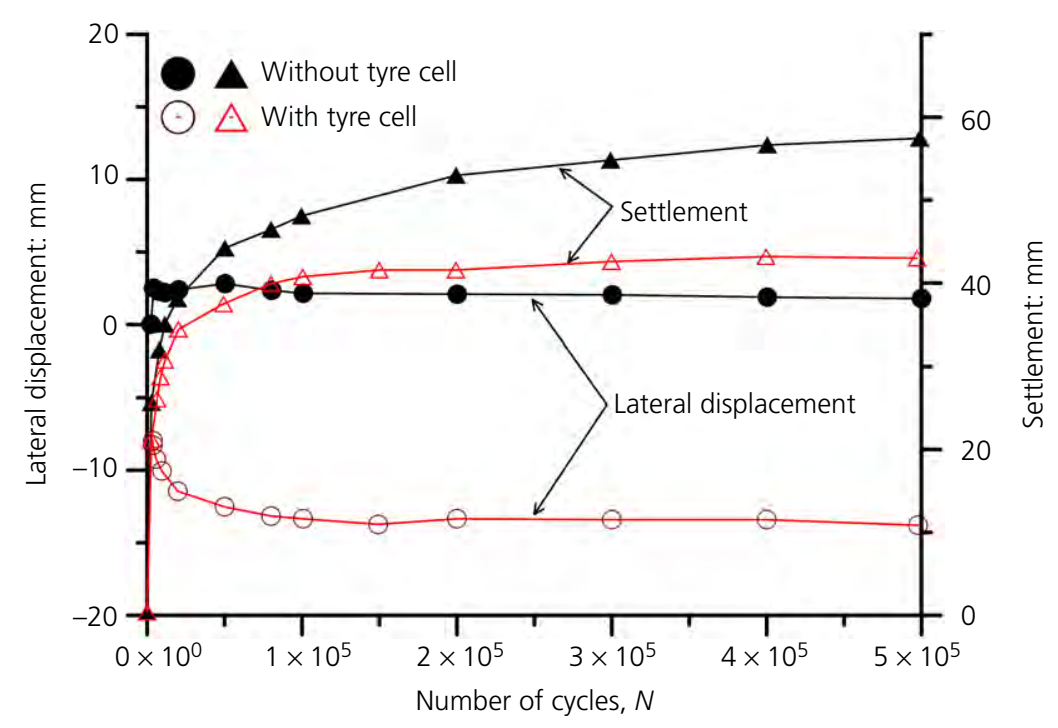

(a)

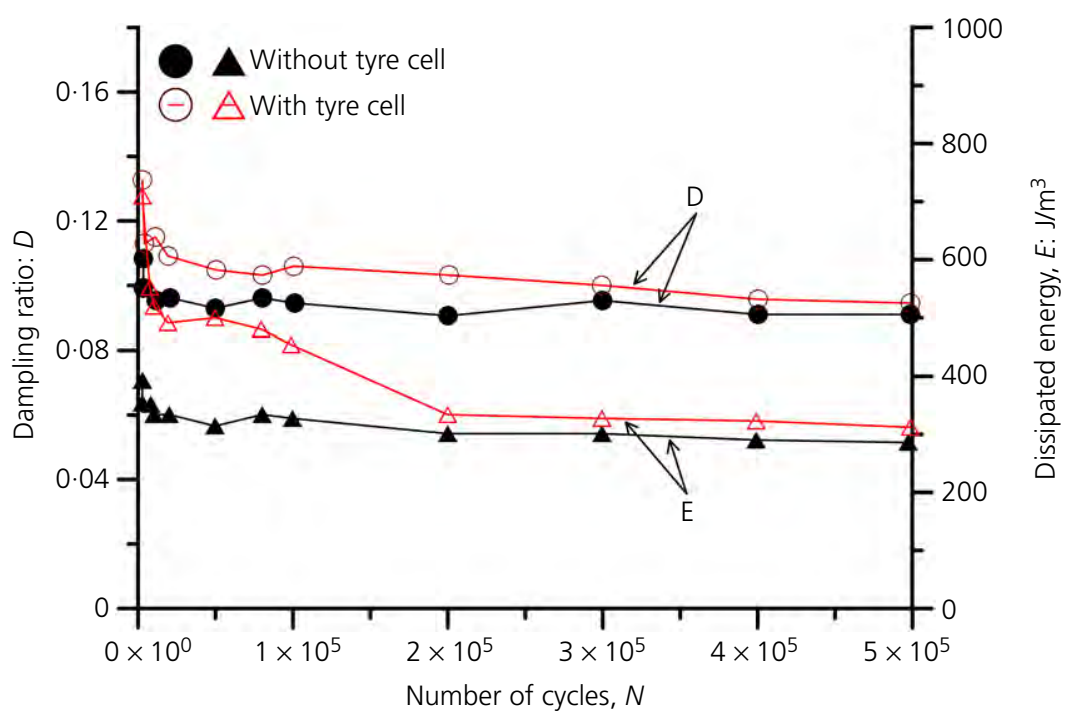

(b)

Figure 14. Cyclic cubical triaxial test results of the test specimen with and without tyre cell: (a) lateral displacement and settlement; (b) damping ratio and dissipated energy (source: modified after Indraratna et al. (2017c))

constant after 100000 cycles. Note that when increasing the loading frequency, the test specimen becomes more deformed. It is evident that the addition of USP and UBM helps to reduce the vertical and lateral deformation of the ballast by a considerable amount. Specifically, under a loading frequency of $15-25 \mathrm{~Hz}$, the inclusion of USP reduces the vertical deformation by $16-47 \%$ and the lateral displacement by $21 \cdot 5-55 \%$, as opposed to a $20-34 \%$ reduction in vertical deformation and $39-44 \%$ in lateral displacement using UBM.

To better understand how the USP and UBM influence the energy-absorbing properties of a rail track, the $D$ and $E$ of the test specimen were examined (Figures 16(c) and 16(d)). The results indicate that $D$ and $E$ are initially high at the beginning of the test, but decrease as $N$ increases, and then stabilise at around $N=100000$. This can be attributed to the particle sliding and breakage which consumed a lot of energy at the initial stage. Note that the inclusion of rubber mats/pats increases the damping capacity of the track and causes a higher dissipation of strain energy. Overall, the track specimen with USP has a higher damping property and energy dissipation than the track with UBM; this indicates that having a rubber mat under the sleeper is a better way of enhancing the energy absorbed by the rail track. This can be further reflected by investigating ballast degradation. Figure 17 shows the BBI of the test specimen under various loading frequencies; as expected, increasing the loading frequency increases the BBI and the addition of rubber mats/pats 


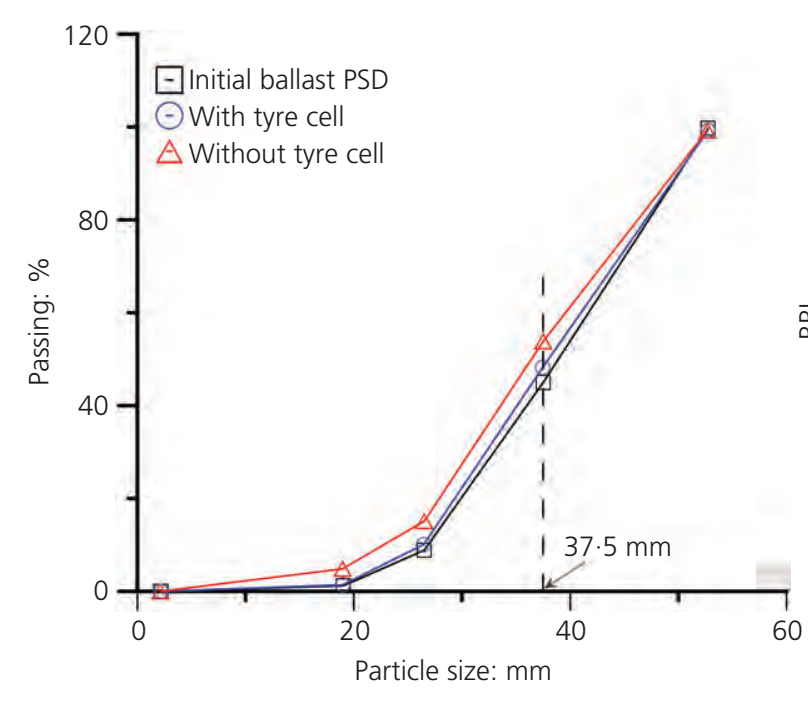

(a)

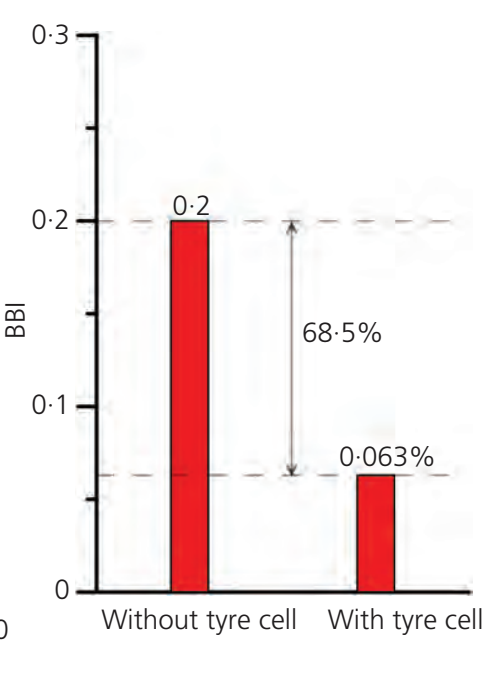

(b)

Figure 15. (a) The gradation of ballast before and after test; (b) BBI (source: data from Indraratna et al. (2017c))

significantly reduces ballast degradation. It is evident that the addition of the USP reduces ballast breakage by more than $50 \%$ while using UBM reduces ballast degradation by almost $19-23 \%$.

Overall, the use of rubber mats/pats in a track enhances its performance by reducing the deformation, increasing the damping property and reducing particle breakage. However, these enhanced performances depend mainly on the physical properties of the rubber mats/pats (e.g. their thickness, stiffness and density), their position (i.e. USP or UBM) and the stiffness of the subgrade (e.g. soft or stiff conditions). Hunt and Wood (2005) indicated that using an elastic element to reduce the stiffness or increasing the thickness of the elastic layer can induce excessive deformation and fatigue damage of track components. In practice, UBM is more effective when the subgrade is stiff - that is, tunnel or bridge conditions (Navaratnarajah and Indraratna, 2017), while the stiffer USP provides a better overall performance (Jayasuriya et al., 2019). The results of this study indicate that by including USP or UBM, the test specimen appears to have a comparable deformation behaviour, whereas the USP will increase the damping property more and thus reduce ballast degradation more.

\section{Conclusions}

This paper has presented some innovative applications for using waste materials (i.e. SFS, CW, FA, RC, recycled tyre cell and rubber mats/pats) in transportation infrastructures, such as using the $\mathrm{CW}$-based granular matrix ( $\mathrm{SFS}+\mathrm{CW}$ or $\mathrm{CW}+\mathrm{FA}$ ) for port reclamation and road subbase, RC blended with mining waste (i.e. SFS and CW) to replace traditional subballast, USP or UBM to minimise ballast deformation and degradation, and waste tyre cells to reinforce the subballast layer.
The following important findings can be drawn from this paper.

- Although compacted CW exhibited sufficient shear strength for the port infrastructure, there was still excessive breakage during shearing when the levels of confinement exceeded $127 \mathrm{kPa}$. To address this shortcoming, blends of compacted CW and SFS were considered. The blends with $30-45 \%$ of SFS content demonstrate sufficient performance to meet the stringent in-service requirements for port infrastructure while minimising the effect of breakage and swelling.

- A mixture of CW and FA is a possible alternative for road infrastructure sublayers. An optimum of $7 \%$ of FA and $6 \%$ of OMC were selected based on compaction, CBR,

UCS and CP tests. The tensile strength tests show that this mixture must be at the OMC or slightly drier than OMC to prevent tension cracking and sustain the highest tensile strength. The mixture was further tested under cyclic loading to mimic field conditions, with the tests showing that the mixture is adequate for a subbase layer if a dry-back condition of $80 \%$ OMC is applied. The mixture can only be used as base material if the loads are not expected to exceed $350 \mathrm{kPa}$.

- Two methods were provided for a SEAL - namely, a $\mathrm{SFS}+\mathrm{CW}+\mathrm{RC}$ mixture and a CW + RC mixture. The cyclic triaxial tests showed that by increasing the amount of $\mathrm{RC}$ in the waste mixture, the damping property and the dissipated energy increased, indicating that by using the $\mathrm{SFS}+\mathrm{CW}+\mathrm{RC}$ matrix it would help to reduce track degradation. This was verified by a large-scale physical model, which proved that adding $10 \%$ of RC in the waste mixture enabled the test specimen to have less ballast degradation and track deformation than the traditional 


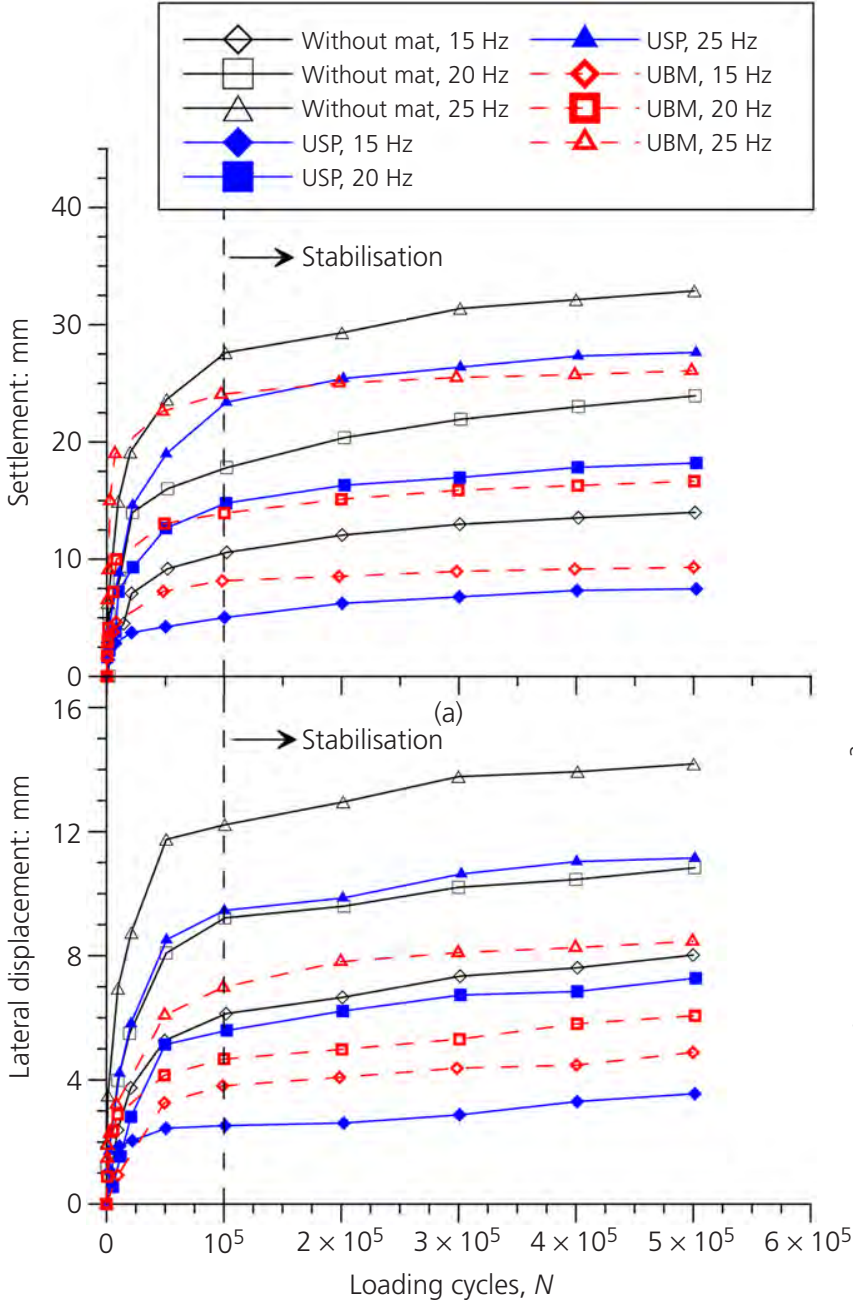

(c)

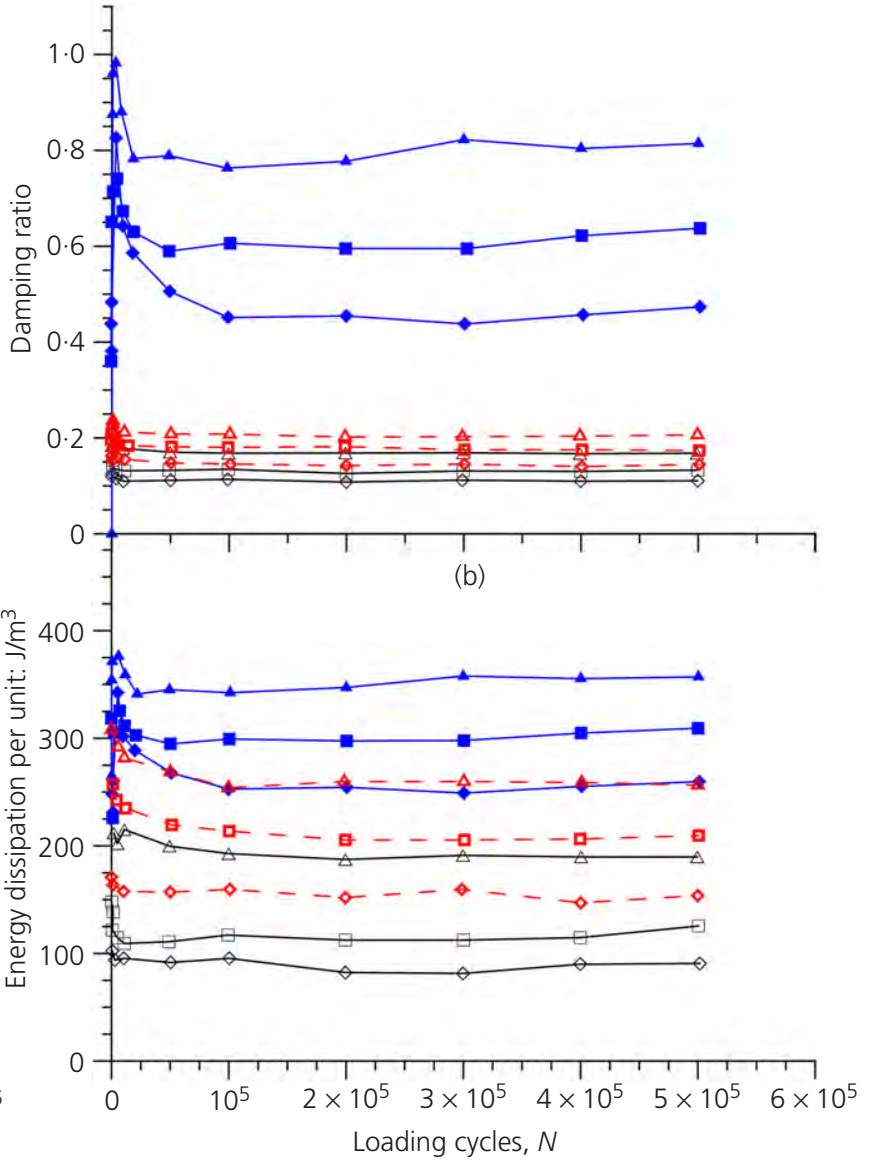

(d)

Figure 16. Cubical triaxial test results of the test specimen with USP or UBM or without rubber mats: (a) settlement and (b) lateral displacement; (c) damping ratio and (d) dissipated energy (source: data from Jayasuriya et al. (2019), Navaratnarajah and Indraratna (2017))

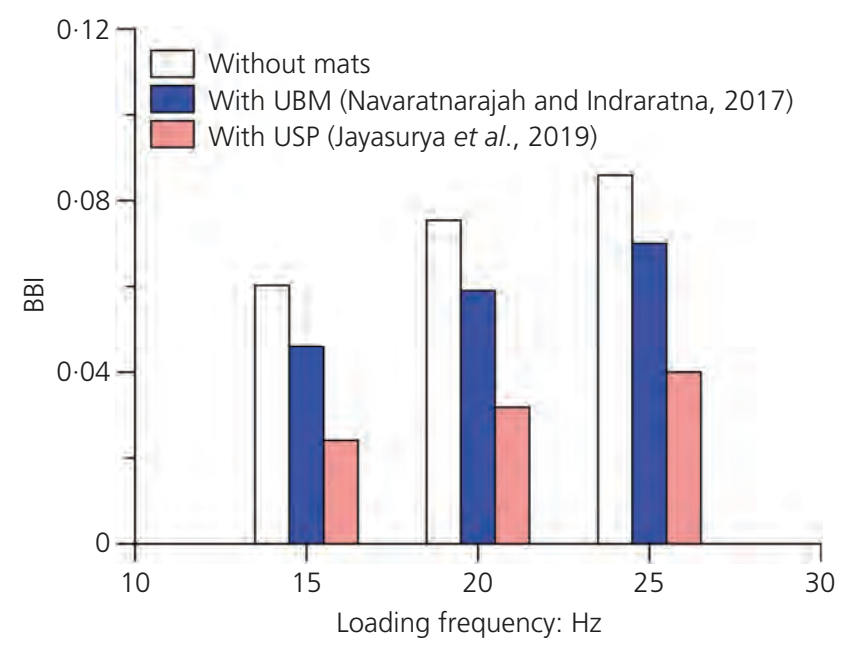

Figure 17. $\mathrm{BBI}$ of the test specimen with USP or UBM or without rubber mats track specimen. As with the $\mathrm{CW}+\mathrm{SFS}+\mathrm{RC}$ mixture, monotonic triaxial tests showed that adding $10 \%$ of rubber to a $\mathrm{CW}+\mathrm{RC}$ mixture compacted with higher energy yielded an acceptable axial deformation for the subballast/capping layer and reduced particle degradation by approximately $50 \%$ more than those without RC.

Most importantly, with the enhanced energy-absorption potential of the $\mathrm{CW}+\mathrm{RC}$ mixture, it can provide a promising inclusion for damping and reducing the vibration generated by passing trains.

- Large-scale cubical triaxial tests were also carried out to investigate the performance of the track specimen reinforced with tyre cells under a heavy-haul loading condition. The tests indicated that tyre cells infilled with traditional capping layer materials can provide considerable lateral confinement and reduce the vertical settlement of a track by approximately $10-12 \mathrm{~mm}$ compared to the sample without tyre cells. Moreover, tyre 
cells can significantly reduce ballast degradation by more than half.

- The large-scale cubical triaxial tests of a track with stiff subgrade and stabilised with USP or UBM had enhanced track performance with less vertical and lateral deformation, higher damping properties and less ballast degradation. By increasing the loading frequency, the deformation and ballast degradation increase. Overall, adding USP or UBM provided a comparable deformation (vertical and lateral) of the track specimen, whereas USP showed a more promising result for its damping capacity and ballast degradation.

\section{Acknowledgements}

The authors acknowledge the financial assistance provided by the Australian Research Council (ARC) Discovery Project (ARC-DP180101916), ARC Linkage Project (LP160100280) and ARC Industry Transformation Training Centre for Advanced Rail Track Technologies (ARC-ITTC-Rail). The assistance provided by industry (Port Kembla Port Corporation (PKPC), Menard Bachy, Coffey Geotechnics, RMS, Douglas Partners, ASMS, South 32, Ecoflex Australia and Tyre Crumbs Australia) in relation to the procurement of material used in this study is gratefully acknowledged. The laboratory assistance provided by $\mathrm{Mr}$ Richard Berndt, $\mathrm{Mr}$ Cameron Neilson, Mr Jordan Wallace, Mr Quang Minh Vu and Mr Salvatore Wedde is appreciated. The content of this paper has been the result of a research study on the reuse of waste materials in transport infrastructure carried out at the UOW for a number of years, which is partially reproduced from published work with kind permission from $A S C E$ Journal of Geotechnical and Geoenvironmental Engineering, ICE Ground Improvement and Transportation Geotechnics. The authors also acknowledge the contributions from past $\mathrm{PhD}$ students and research associates, namely Dr Chazath Kaliboullah, Dr Ali Tasalloti, Dr Gabrielle Chiaro, Dr Qideng Sun, Dr Chamindi Jayasuriya and Dr Jayan Vinod, as well as industry partners, namely, Geoff McIntosh (Douglas Partners), Phillip Vincent (Menard Group), Tonilee Andrews (PKPC), Jim Grant (Ecoflex), Peter Meers and Robyn Lyster (Roads and Maritimes Services).

\section{REFERENCES}

Ahmaruzzaman M (2010) A review on the utilization of fly ash. Progress in Energy and Combustion Science 36(3): 327-363.

Arulrajah A, Maghool F, Mohammadinia A, Mirzababaei M and Horpibulsuk S (2020a) Wheel tracker testing of recycled concrete and tyre aggregates in Australia. Geotechnical Research 1-9, https://doi.org/10.1680/jgere.19.00038.

Arulrajah A, Naeini M, Mohammadinia A, Horpibulsuk S and Leong M (2020b) Recovered plastic and demolition waste blends as railway capping materials. Transportation Geotechnics 22: 100320 .

ASTM (2009) D6951/D6951M: Standard test method for use of the dynamic cone penetrometer in shallow pavement application. ASTM International, West Conshohocken, PA, USA.
ASTM (2013) D5311/D5311M: Standard test method for load controlled cyclic triaxial strength of soil. ASTM International, West Conshohocken, PA, USA.

Austroads (2007) AGPT-T053-07: Determination of Permanent Deformation and Resilient Modulus Characteristics of Unbound Granular Materials Under Drained Conditions. Austroads Ltd., Sydney, New South Wales, Australia.

Brulliard C, Cain R, Do D et al. (2012) The Australian Recycling Sector. Net Balance; Department of Sustainability, Environment, Water, Population and Communities, Canberra, Australian Capital Territory (ACT), Australia.

Chiaro G, Indraratna B, Tasalloti S and Rujikiatkamjorn C (2015) Optimisation of coal wash-slag blend as a structural fill. Proceedings of the Institution of Civil Engineers - Ground Improvement 168(GI1): 33-44, https://doi.org/10.1680/ grim.13.00050.

Cho SD, Kim JM, Kim JH and Lee KW (2007) Utilization of waste tires to reduce railroad vibration. In Materials Science Forum 544-545: 637-640, https://doi.org/10.4028/www.scientific.net/MSF. 544-545.637.

Costa PA, Calçada R and Cardoso AS (2012) Ballast mats for the reduction of railway traffic vibrations. Numerical study. Soil Dynamics and Earthquake Engineering 42: 137-150.

Davies P, Philip RED and James DM (2011) Geotechnical design for the Port Botany expansion project, Sydney. Proceedings of the Institution of Civil Engineers - Geotechnical Engineering 164(9): 149-167, https://doi.org/10.1680/geng.10.00052.

Downs LA, Humphrey DN, Katz LE and Rock CA (1996) Water quality effects of using tire chips below the groundwater table, technical services division, technical paper. Department of Civil and Environmental Engineering, University of Maine, Orono, Maine.

Edil TB and Bosscher PJ (1992) Development of Engineering Criteria for Shredded or Whole Tires in Highway Applications. Department of Civil and Environmental Engineering, University of Wisconsin, Madison, WI, USA, Report No. WI 14-92.

Fityus S, Hancock G and Wells T (2008) Geotechnical characteristics of coalmine spoil. Australian Geomechanical Journal 43(3): 13-22.

Heitor A, Indraratna B, Rujikiatkamjorn C, Chiaro G and Tasalloti SA (2014) Evaluation of the coal wash and steel furnace slag blends as effective reclamation fill for port expansion. In 7 th International Congress on Environmental Geotechnics (Bouazza A, Yuen STS and Brown B (eds)). Engineers Australia, Melbourne, Australia, pp. 972-979.

Heitor A, Indraratna B, Kaliboullah Cl, Rujikiatkamjorn C and McIntosh GW (2016) Drained and undrained shear behavior of compacted coal wash. Journal of Geotechnical and Geoenvironmental Engineering 142(5): 04016006.

Humphrey DN, Katz LE and Blumenthal M (1997) Water quality effects of tire chip fills placed above the groundwater table. In Testing Soil Fixed with Waste or Recycled Materials (Wasemiller MA and Hoddinott KB (eds)). American Society for Testing and Materials, West Conshohocken, PA, USA, pp. 299-313, https://doi.org/ 10.1520/STP15659S.

Hunt G and Wood J (2005) Review of the effect of track stiffness on track performance. RSSB, Research Project 372.

Indraratna B (1994) Geotechnical characterization of blended coal tailings for construction and rehabilitation work. Quarterly Journal of Engineering Geology and Hydrogeology 27(4): 353-361.

Indraratna B, Gasson I and Chowdhury R (1994) Utilization of compacted coal tailings as a structural fill. Canadian Geotechnical Journal 31(5): 614-623.

Indraratna B, Lackenby J and Christie D (2005) Effect of confining pressure on the degradation of ballast under cyclic loading. Géotechnique 55(4): 325-328, https://doi.org/10.1680/geot. 2005.55.4.325. 
Indraratna B, Ngo NT and Rujikiatkamjorn C (2011) Behavior of geogrid-reinforced ballast under various levels of fouling. Geotextiles and Geomembranes 29(3): 313-322.

Indraratna B, Biabani MM and Nimbalkar S (2014) Behavior of geocell-reinforced subballast subjected to cyclic loading in plane-strain condition. Journal of Geotechnical and Geoenvironmental Engineering 141(1): 04014081.

Indraratna B, Qi Y and Heitor A (2017a) Evaluating the properties of mixtures of steel furnace slag, coal wash, and rubber crumbs used as subballast. Journal of Materials in Civil Engineering 30(1): 04017251.

Indraratna B, Sun Q and Grant J (2017b) Behaviour of subballast reinforced with used tyre and potential application in rail tracks. Transportation Geotechnics 12: 26-36.

Indraratna B, Sun Q, Heitor A and Grant J (2017c) Performance of rubber tire-confined capping layer under cyclic loading for railroad conditions. Journal of Materials in Civil Engineering 30(3): 06017021.

Indraratna B, Ferreira FB, Qi Y and Ngo TN (2018) Application of geoinclusions for sustainable rail infrastructure under increased axle loads and higher speeds. Innovative Infrastructure Solutions 3(1): 69.

Indraratna B, Qi Y, Ngo TN et al. (2019a) Use of geogrids and recycled rubber in railroad infrastructure for enhanced performance. Geosciences 9(1): 30.

Indraratna B, Rujikiatkamjorn C, Tawk M and Heitor A (2019b) Compaction, degradation and deformation characteristics of an energy absorbing matrix. Transportation Geotechnics 19: 74-83.

Jayasuriya C, Indraratna B and Ngo TN (2019) Experimental study to examine the role of under sleeper pads for improved performance of ballast under cyclic loading. Transportation Geotechnics 19: 61-73.

Jeffs T and Tew G (1991) A Review of Track Design Procedures Sleepers and Ballast, Railways of Australia. Australian Government Publishing Service, Melbourne, vol. 2.

Kabir E, Haque A and Bouazza A (2006) Effect of cyclic loading on filtration behaviour of subballast material. In Advances in Unsaturated Soil, Seepage, and Environmental Geotechnics (Lu N, Hoyos LR and Reddi L (eds)). American Society of Civil Engineers, Reston, VA, USA, pp. 180-186.

Kaliboullah Cl, Indraratna B, Rujikiatkamjorn C and Heitor A (2015) Evaluation of coal wash as a potential structural fill material for port reclamation. Proceedings of the 12th Australia New Zealand Conference on Geomechanics ( ANZ 2015): The Changing Face of the Earth-Geomechanics \& Human Influence, Wellington, New Zealand. The Conference Company Ltd., Auckland, New Zealand, pp. 199-206.

Malasavage NE, Jagupilla S, Grubb DG, Wazne M and Coon WP (2012) Geotechnical performance of dredged material - steel slag fines blends: laboratory and field evaluation. Journal of Geotechnical and Geoenvironmental Engineering 138(8): 981-991.

Mudd GM (2010) The environmental sustainability of mining in Australia: key mega-trends and looming constraints. Resources Policy 35(2): 98-115.

Naeini M, Mohammadinia A, Arulrajah A, Horpibulsuk S and Leong M (2020) Stiffness and strength characteristics of demolition waste, glass and plastics in railway capping layers. Soils and Foundations https://doi.org/10.1016/j.sandf.2019.12.009.

Navaratnarajah SK and Indraratna B (2017) Use of rubber mats to improve the deformation and degradation behavior of rail ballast under cyclic loading. Journal of Geotechnical and Geoenvironmental Engineering 143(6): 04017015.

Navaratnarajah SK, Indraratna B and Ngo NT (2018) Influence of under sleeper pads on ballast behavior under cyclic loading: experimental and numerical studies. Journal of Geotechnical and Geoenvironmental Engineering 144(9): 04018068.

Nimbalkar S and Indraratna B (2016) Improved performance of ballasted rail track using geosynthetics and rubber shockmat. Journal of Geotechnical and Geoenvironmental Engineering 142(8): 04016031.

NSW EPA (NSW Environment Protection Authority) (2014a) Resource Recovery Exemption, the Protection of the Environment Operations (Waste) Regulation 2014 - The Coal Washery Rejects Exemption. EPA, Parramatta, New South Wales (NSW), Australia. See http://www.epa.nsw.gov.au/resources/waste/rre14-coal-wash-rejects. pdf (accessed 24/11/2014).

NSW EPA (2014b) Resource Recovery Exemption the Protection of the Environment Operations (Waste) Regulation 2014 - The Steel Furnace Slag Exemption. EPA, Parramatta, New South Wales (NSW), Australia. See http://www.epa.nsw.gov.au/resources/ waste/rre14-steel-furnace-slag.pdf (accessed 21/07/2017).

Pusadkar SS and Ramasamy G (2005) Collapse behavior of compacted coal ash fills. Geotechnical Testing Journal 28(3): 297-304.

Qi Y, Indraratna B, Heitor A and Vinod JS (2018a) Closure to 'effect of rubber crumbs on the cyclic behavior of steel furnace slag and coal wash mixtures' by Yujie Qi, Buddhima Indraratna, Ana Heitor, and Jayan S. Vinod. Journal of Geotechnical and Geoenvironmental Engineering 145(1): 07018035.

Qi Y, Indraratna B, Heitor A and Vinod JS (2018b) Effect of rubber crumbs on the cyclic behavior of steel furnace slag and coal wash mixtures. Journal of Geotechnical and Geoenvironmental Engineering 144(2): 04017107.

Qi Y, Indraratna B and Vinod JS (2018c) Dynamic properties of mixtures of waste materials. Proceedings of GeoShanghai 2018 International Conference: Advances in Soil Dynamics and Foundation Engineering (Qiu T, Tiwari B and Zhang Z (eds)). Springer, Singapore, GSIC 2018, pp. 308-317.

Qi Y, Indraratna B and Coop MR (2019a) Predicted behavior of saturated granular waste blended with rubber crumbs. International Journal of Geomechanics 19(8): 04019079.

Qi Y, Indraratna B, Heitor A and Vinod J (2019b) The influence of rubber crumbs on the energy absorbing property of waste mixtures. In Geotechnics for Transportation Infrastructure (Sundaram R, Telangrao SJ and Havanagi V (eds)). Springer, Singapore, vol. 29, pp. 271-281.

Radampola SS, Gurung N, McSweeney T and Dhanasekar M (2008) Evaluation of the properties of railway capping layer soil. Computers and Geotechnics 35(5): 719-728.

Rujikiatkamjorn C, Indraratna B and Chiaro G (2013) Compaction of coal wash to optimise its utilisation as water-front reclamation fill. Geomechanics and Geoengineering 8(1): 36-45.

SA (Standards Australia) (2008) AS 5101.4-2008: Methods for preparation and testing of stabilized materials - Unconfined compressive strength of compacted materials. Standards Australia Limited, Sydney, Australia.

SA (2014) AS 1289.6.1.1:2014: Methods of testing Soils for engineering purposes - Soil strength and consolidation tests - Determination of the California bearing ratio of a soil - Standard laboratory method for a remoulded specimen. Standards Australia Limited, Sydney, Australia.

SA (2015) 2758.7: Aggregates and rock for engineering purposes, Part 7: Railway ballast. Standards Australia Limited, Sydney, NSW, Australia.

Saberian M, Li J, Nguyen B and Wang G (2018) Permanent deformation behaviour of pavement base and subbase containing recycle concrete aggregate, coarse and fine crumb rubber. Construction and Building Materials 178: 51-58.

Schneider P, Bolmsvik R and Nielsen JC (2011) In situ performance of a ballasted railway track with under sleeper pads. Proceedings of the 
Institution of Mechanical Engineers, Part F: Journal of Rail and Rapid Transit 225(3): 299-309.

Sol-Sánchez M, Moreno-Navarro F and Rubio-Gámez MC (2015) The use of elastic elements in railway tracks: a state of the art review. Construction and Building Materials 75: 293-305.

Sol-Sánchez M, Moreno-Navarro F, Pérez R and Rubio-Gámez M (2019) Defining the process of including sustainable rubber particles under sleepers to improve track behaviour and performance. Journal of Cleaner Production 227: 178-188.

Suddeepong A, Sari N, Horpibulsuk S, Chinkulkijniwat A and Arulrajah A (2020) Interface shear behaviours between recycled concrete aggregate and geogrids for pavement applications. International Journal of Pavement Engineering 21(2): 228-235.

Sun Q, Indraratna B and Heitor A (2019) Behaviour of a capping layer reinforced with recycled tyres. Ground Improvement 172(3): 127-137, https://doi.org/10.1680/jgrim.18.00030.

Tasalloti SMA, Indraratna B, Chiaro G and Heitor A (2015a) Field investigation on compaction and strength performance of two coal wash-BOS slag mixtures. International Foundations Congress and Equipment Expo 2015, IFCEE 2015, San Antonio, $T X, U S A$ (Iskander M, Suleiman MT, Anderson JB and
Laefer DF (eds)). American Society of Civil Engineers, Reston, VA, USA, Geotechnical Special Publication 256, pp. 2359-2368. Tasalloti SM, Indraratna B, Rujikiatkamjorn C, Heitor A and Chiaro G (2015b) A laboratory study on the shear behavior of mixtures of coal wash and steel furnace slag as potential structural fill. Geotechnical Testing Journal 38(4): 361-372.

Trani LDO and Indraratna B (2010) Assessment of subballast filtration under cyclic loading. Journal of Geotechnical and Geoenvironmental Engineering 136(11): 1519-1528.

Wang G (2010) Determination of the expansion force of coarse steel slag aggregate. Construction and Building Materials 24(10): 1961-1966.

Wang D, Tawk M, Indraratna B, Heitor A and Rujikiatkamjorn C (2019) A mixture of coal wash and fly ash as a pavement substructure material. Transportation Geotechnics 21: 100265.

Xue Y, Wu S, Hou H and Zha J (2006) Experimental investigation of basic oxygen furnace slag used as aggregate in asphalt mixture Journal of Hazardous Materials 138(2): 261-268.

Yildirim IZ and Prezzi M (2015) Geotechnical properties of fresh and aged basic oxygen furnace steel slag. Journal of Materials in Civil Engineering 27(12): 04015046.

\section{How can you contribute?}

To discuss this paper, please email up to 500 words to the editor at journals@ice.org.uk. Your contribution will be forwarded to the author(s) for a reply and, if considered appropriate by the editorial board, it will be published as discussion in a future issue of the journal.

Proceedings journals rely entirely on contributions from the civil engineering profession (and allied disciplines). Information about how to submit your paper online is available at www.icevirtuallibrary.com/page/authors, where you will also find detailed author guidelines. 